ARTICLE

https://doi.org/10.1038/s41467-019-12019-6

\title{
Mechanism of centromere recruitment of the CENP-A chaperone HJURP and its implications for centromere licensing
}

\author{
Dongqing Pan (10 1, Kai Walstein (10 ${ }^{1}$, Annika Take ${ }^{1}$, David Bier ${ }^{1}$, Nadine Kaiser ${ }^{2}$ \& Andrea Musacchio ${ }^{1,3}$
}

Nucleosomes containing the histone H3 variant CENP-A are the epigenetic mark of centromeres, the kinetochore assembly sites required for chromosome segregation. HJURP is the CENP-A chaperone, which associates with Mis18 $\alpha$, Mis18 $\beta$, and M18BP1 to target centromeres and deposit new CENP-A. How these proteins interact to promote CENP-A deposition remains poorly understood. Here we show that two repeats in human HJURP proposed to be functionally distinct are in fact interchangeable and bind concomitantly to the

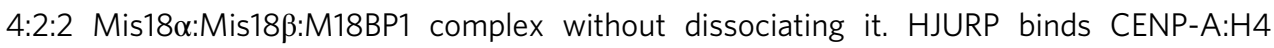
dimers, and therefore assembly of CENP-A:H4 tetramers must be performed by two Mis18 $\alpha$ :M18BP1:HJURP complexes, or by the same complex in consecutive rounds. The Mis18 $\alpha \mathrm{N}$-terminal tails blockade two identical HJURP-repeat binding sites near the Mis18 $\alpha \beta$ $\mathrm{C}$-terminal helices. These were identified by photo-cross-linking experiments and mutated to separate Mis18 from HJURP centromere recruitment. Our results identify molecular underpinnings of eukaryotic chromosome inheritance and shed light on how centromeres license CENP-A deposition.

\footnotetext{
${ }^{1}$ Department of Mechanistic Cell Biology, Max Planck Institute of Molecular Physiology, Otto-Hahn-Straße 11, 44227 Dortmund, Germany. ${ }^{2}$ Department of Chemical Biology, Max Planck Institute of Molecular Physiology, Otto-Hahn-Straße 11, 44227 Dortmund, Germany. ${ }^{3}$ Centre for Medical Biotechnology, Faculty of Biology, University Duisburg-Essen, Universitätsstrasse, 45141 Essen, Germany. Correspondence and requests for materials should be addressed to D.P. (email: dongqing.pan@mpi-dortmund.mpg.de) or to A.M. (email: andrea.musacchio@mpi-dortmund.mpg.de)
} 
D uring cell division in eukaryotes, kinetochores provide a crucial point of microtubule attachment and are essential for chromosome bi-orientation on the mitotic spindle ${ }^{1}$. On each chromosome, the kinetochore emerges from a specialized chromosomal domain named the centromere, whose hallmark is the strong enrichment of centromeric protein $\mathrm{A}$, a histone $\mathrm{H} 3$ variant $(\mathrm{CENP}-\mathrm{A})^{2-5}$. Despite its very high relative abundance in comparison to other chromosome domains, CENP-A at centromeres co-exists with an excess of canonical $\mathrm{H} 3^{6}$, and yet it is absolutely required for kinetochore assembly. Substantial biochemical and structural evidence has now accumulated that CENP-A becomes embedded in an octameric nucleosome broadly similar to canonical nucleosomes ${ }^{2,7}$. Notable sequence differences, however, are sufficient to allow direct recruitment to the CENP-A nucleosome of two inner kinetochore proteins in the so-called constitutive centromere-associated network (CCAN), CENP-C and CENP-N, in turn permitting the hierarchical assembly of the entire kinetochore ${ }^{1}$.

The levels of CENP-A are constant across generations, suggesting that the amount of newly deposited CENP-A matches the levels of existing CENP-A ${ }^{8-10}$. With the exception of a handful of organisms, however, the enrichment of CENP-A within the centromeric domain appears to be independent of specific DNA sequences $^{2-5}$. This observation is the basis of the concept that centromere identity, which exquisitely depends on CENP-A, is inherited epigenetically. This has shifted the focus onto the mechanisms that allow the centromeric levels of CENP-A to be maintained through cell division, leading to the pioneering discovery of factors involved in new CENP-A deposition ${ }^{11-14}$.

In many organisms, including humans, dilution of CENP-A occurs during DNA replication, when the CENP-A pool is equally partitioned to the sister chromatids and the resulting vacancies are filled with histone $\mathrm{H} 3^{15}$. To compensate for replicationcoupled dilution, new CENP-A is then deposited in the very early G1 phase of the cell cycle ${ }^{16,17}$. Once deposited, CENP-A is then stably inherited, with little or no dissipation even over extremely long periods ${ }^{16,18-20}$. At least four core factors of the CENP-A loading machinery have been identified. In humans, these include the two-subunit Mis18 complex (Mis18a and Mis18ß; relevant proteins are illustrated schematically in Fig. 1a), Mis18-binding protein 1 (M18BP1, also known as KNL2), and Holliday junction recognition protein (HJURP) $)^{11-14,21}$. In addition, several accessory factors and regulators of CENP-A deposition have been identified, including, among others, RSF1, MgcRacGAP, Condensin II, and KAT722-26.

HJURP is a histone assembly factor that stabilizes soluble CENP-A:H4 dimers before incorporation into centromeric nucleosomes in late telophase/early G1 ${ }^{13,14,27}$. The CENP-A:H4 binding region of human (Hs) HJURP, in the protein's $\mathrm{N}$ terminal region, defines a class of CENP-A assembly factors with common ancestry. It includes the Saccharomyces cerevisiae protein $\mathrm{Scm} 3$, which acts as deposition factor for the CENP-A ortholog Cse ${ }^{28-31}$. Sequence similarity of these factors is limited to the CENP-A:H4 binding domain ${ }^{28}$. A region in the central domain (CD) of HsHJURP (also identified as mid domain, HMD) has been implicated in DNA binding ${ }^{32}$. Two additional sequence-related HJURP C-terminal domains (HCTD1 and HCTD2) within the carboxy terminal half of the protein ${ }^{28}$ are sufficient to promote robust centromere recruitment of HJURP in the G1 phase ${ }^{33}$. Here, we refer to the HCTDs as repeat 1 and repeat 2 (R1 and R2; Fig. 1a, b. An alignment of mammalian HJURP is shown in Supplementary Fig. 1).

Because HJURP localization is sufficient for CENP-A deposition $^{34-36}$, several mechanisms control the timing and localization of HJURP recruitment. Central to these mechanisms are M18BP1, Mis18a, and Mis18 $\beta$. Mis18 $\alpha$ and Mis18 $\beta$ form a tight 2-subunit complex (which we refer to here as the Mis $18^{\text {core }}$ of the Mis18 complex) and interact tightly but in a regulated, transient manner, with M18BP1 to assemble the Mis18 complex (Fig. 1c). The Mis18 complex precedes HJURP to centromeres and is required for its recruitment there ${ }^{12,25,34,36-41}$. While the mechanism of centromere recruitment of the Mis18 complex remains partly unclear, binding to CENP-A nucleosomes or CENP-C appears to contribute $35-39,42-47$. HJURP itself may specify additional interactions with inner kinetochore proteins ${ }^{35,40,41,48}$.

In analogy with the licensing events that limit the initiation of DNA replication to once per cell cycle, several factors have been proposed to promote licensing steps that limit CENP-A deposition to once per cycle ${ }^{3}$. Among the factors required for deposition, positive and negative regulation by the kinase activities of the polo-like kinase 1 (PLK1) and cyclin-dependent kinases 1 and $2(\mathrm{CDK} 1 / 2)$, respectively, have emerged for their prominence. PLK1 associates with the Mis18 complex at kinetochores in telophase/early G1, and its activity is required for deposition ${ }^{49}$. Cyclin-dependent kinase (Cdk) phosphorylation of HJURP prevents binding to Mis18 and centromere localization ${ }^{32,50,51}$ (Fig. 1c, left). Cdk phosphorylation of M18BP1 also inhibits its association with Mis18 $18^{\text {core }}$ and centromere recruitment ${ }^{49,50,52-54}$. As a further licensing step, it has been proposed that binding of HJURP to a Mis18a:Mis18 $\beta$ core tetramer activates HJURP for CENP-A deposition while causing dissociation of the Mis18a: Mis18 $\beta$ tetramer into a dimer that is unable to rebind centromeres $^{8}$. Subsequent work, however, re-examined the stoichiometry of the Mis 18 core complex and found it to consist of a $4: 2$ hexamer ${ }^{52,54}$, as discussed more thoroughly in the Results section. Finally, M18BP1 release from the centromere was shown to be required for efficient CENP-A deposition ${ }^{50}$. Collectively, these events have been interpreted as manifestations of a global licensing mechanism controlling the deposition machinery so that deposition is limited to a single round.

Work of biochemical reconstitution revealed aspects of kinetochore organization that led us to hypothesize a new mechanistic model for why newly deposited CENP-A is fixed on the levels of existing CENP-A ${ }^{1}$. Specifically, various observations suggest that the substrate recognized by the CENP-A deposition machinery is an inner kinetochore structure consisting of neighboring CENP$\mathrm{A}$ and $\mathrm{H} 3$ nucleosomes ${ }^{1}$ connected by inner kinetochore proteins in the CCAN, especially CENP-C and CENP-T ${ }^{20,55-58 ~(F i g . ~ 1 c, ~}$ right). We speculated that processing of this substrate through eviction of the paired $\mathrm{H} 3$ nucleosome and its replacement with a new CENP-A nucleosome will cause the deposition machinery to dissociate in a manner similar to the dissociation of enzymes from their products ${ }^{1}$. While this model remains unproven, it provides a conceptual alternative to models postulating that prevention of multiple rounds of deposition requires the active dissociation of the Mis $18^{\text {core }}$ complex by HJURP or the active dissociation of M18BP1 from centromeres ${ }^{8,50}$. Both the dinucleosome model and the two dissociation models discussed above predict that CENP-A content will be doubled during deposition, but identify different causes for this phenomenon: exhaustion of the reaction substrate on one hand, and active dissociation of the enzyme on the other.

Testing the significance of these various models requires a detailed understanding of, and exquisite control over, the interactions that promote CENP-A deposition. While progress has been made in this direction, remaining gaps of knowledge prevent formal proof of competing hypotheses. Here, we contribute to fill this gap by analyzing the mechanism of the interaction of HJURP with Mis $18^{\text {core }}$ and M18BP1 using a powerful combination of tools in vitro and in vivo. With results that seem irreconcilable with the Mis18 dissociation model $^{8}$, we demonstrate that the 
a

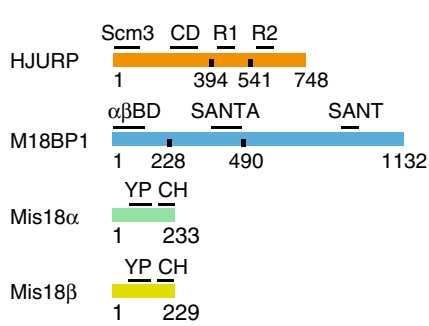

C

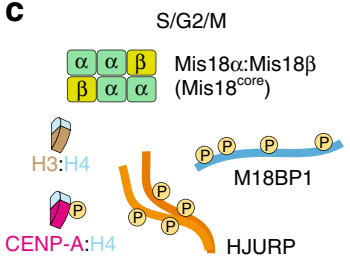

(P) Phosphorylation by CDK

P Phosphorylation by PLK1

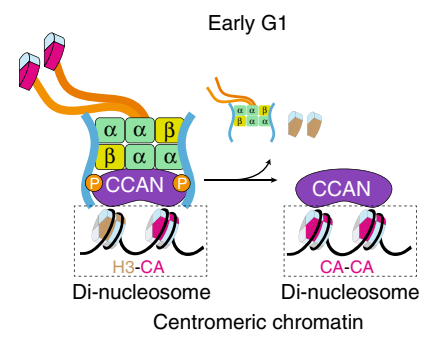

Centromeric chromatin

b

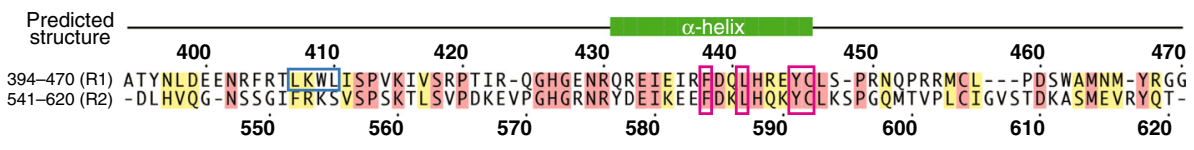

d

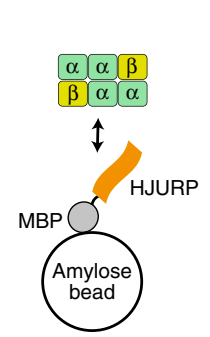

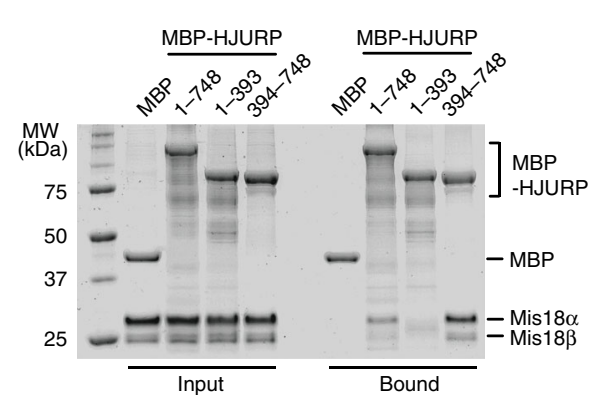

f

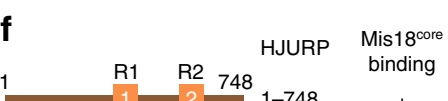

e
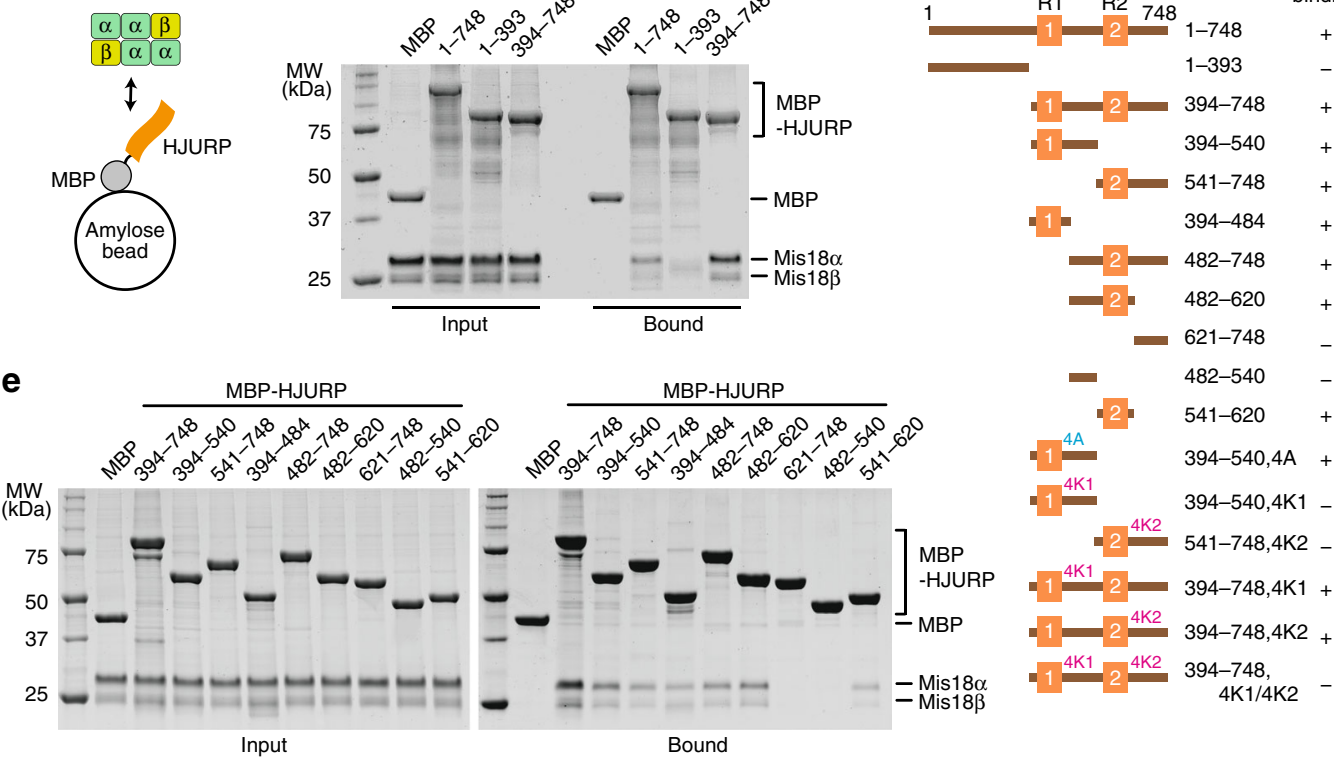

$-2=394-540+$

1. 394-484

$-2-482-748$

-2 482-620+

621-748

-2. $\begin{aligned} & 482-540 \text { - } \\ & 541-620+\end{aligned}$

$14 \mathrm{~A} \quad 394-540,4 \mathrm{~A}+$ $1^{4 \mathrm{~K} 1} \quad 394-540,4 \mathrm{~K} 1$ $-2^{4 \mathrm{~K} 2} 541-748,4 \mathrm{~K} 2-$

$=1 \frac{4 \mathrm{~K} 1}{2}-2-394-748,4 \mathrm{~K} 1+$

$-1-2^{4 \mathrm{~K} 2} 394-748,4 \mathrm{~K} 2+$ - $1^{4 \mathrm{~K} 1}-2 \frac{4 \mathrm{~K} 2}{394-748,}$ $4 \mathrm{~K} 1 / 4 \mathrm{~K} 2-$

g

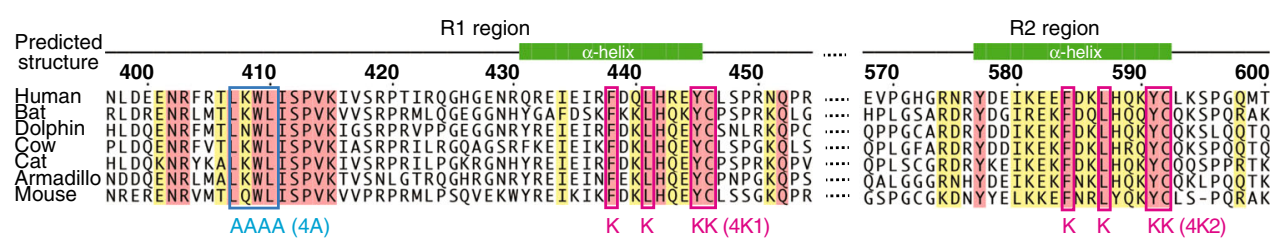

h

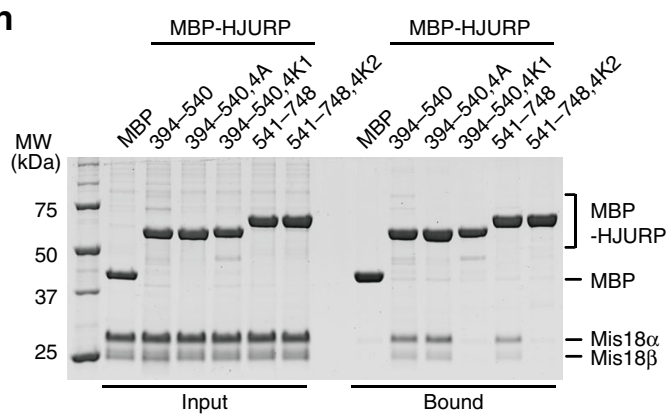

interaction with HJURP does not cause dissociation of the Mis18core complex, regardless of the presence of M18BP1. We show that the CENP-A deposition complex contains M18BP1, Mis18 ${ }^{\text {core }}$, and HJURP in defined stoichiometries, with the latter present in a single copy. The isolated R1 and R2 repeats are monomeric, and largely functionally interchangeable if provided with the appropriate dosage. They bind, as part of the same

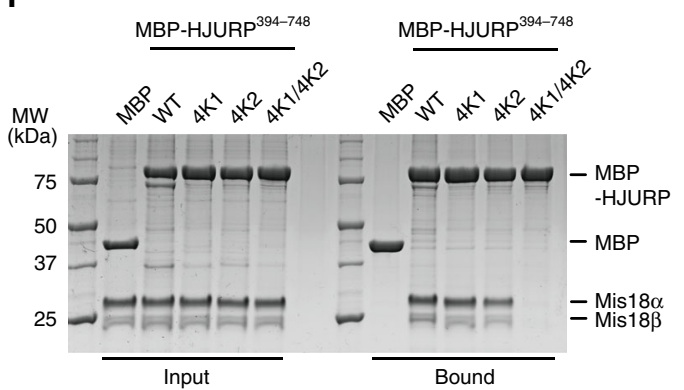

HJURP molecule, to equivalent sites on the two trimeric C-terminal helical bundles of the Mis18 complex. Conversely, we find no evidence that HJURP dimerization is important for the interaction with Mis18, as proposed previously ${ }^{33}$. By ambercodon suppression ${ }^{59,60}$ we map the Mis18-binding sites for the R1 and R2 repeat by mass spectrometry, and validate them by mutational analysis in vitro and in cells. Collectively, our results 
Fig. 1 Both HJURP C-terminal repeats, R1 and R2, bind Mis18core complex. a Domain organization of HJURP, M18BP1, Mis18 $\alpha$, and Mis18 $\beta$. CD central domain, R1 repeat 1, R2 repeat 2, $\alpha \beta B D$ Mis18 $\alpha$ :Mis18 $\beta$ binding domain, YP Yippee domain, CH C-terminal helix. b Sequence alignment of R1 and R2 of HsHJURP. Multiple sequence alignment was performed using ClustalW85. Secondary structure prediction was performed using PSIPRED 86 . Residues identical in all sequences are shaded red, and conserved substitutions with similar properties are shaded yellow. Blue and magenta boxes indicate residues mutated to 4A, 4K1, or 4K2 as indicated in $\mathbf{g}$. c Schematic model of the phosphorylation-regulated assembly of the CENP-A deposition machinery. d, e Amylose-resin pull-down assays were performed to identify the Mis18core-binding regions of HJURP. Proteins were incubated at $5 \mu M$ in binding buffer $A$ containing $30 \mathrm{mM}$ HEPES pH 7.5, $300 \mathrm{mM}$ sodium chloride, $1 \mathrm{mM}$ TCEP, 0.01\% Tween-20. The gels were stained with Coomassie brilliant blue (CBB). f Summary of the pull-down results. $\mathbf{g}$ Sequence alignment of HJURP sequences around R1 and R2 regions from different mammalian species. $\mathbf{h}, \mathbf{i}$ Amyloseresin pull-down assays for testing the binding of Mis18core and HJURP variants with 4A, 4K1, and 4K2 mutations

unveil fundamental aspects of a crucial molecular mechanism required for chromosome segregation and intergenerational genetic inheritance, and pave the way for future mechanistic studies.

\section{Results}

Interaction of $\mathrm{R} 1$ and $\mathrm{R} 2$ in HJURP with Mis18 ${ }^{\text {core }}$. The Cterminal region of HJURP is sufficient to bind the Mis $18^{\text {core }}$ complex $^{33,41,51}$. Within this region, the $\mathrm{R} 1$ repeat promotes binding to the Mis $18^{\text {core }}$ complex, whereas R2 promotes HJURP dimerization $^{33,51}$. Secondary structure prediction programs indicate that the C-terminal region of HJURP is, for the most part, intrinsically disordered (Supplementary Fig. 1), with few exceptions, like the $\mathrm{R} 1$ and $\mathrm{R} 2$ repeats, which are predicted to contain a single $\alpha$-helix. Given the generally modest stability of isolated $a$-helices, we surmise that this conformation is only adopted after binding to the Mis18 complex (R1) or after the proposed dimerization (R2).

To validate the interaction mechanism, we generated several Cterminal fusions of HJURP fragments to maltose binding protein (MBP) and immobilized them on solid phase. We then incubated the fusion proteins with the Mis $18^{\text {core }}$ complex, washed away unbound proteins, and evaluated the composition of beads by SDS-PAGE analysis. In line with the previous reports ${ }^{33,51}$, fulllength HJURP (HJURP ${ }^{1-748}$ ) and HJURP394-748 bound to Mis18 ${ }^{\text {core, }}$, while HJURP ${ }^{1-393}$ did not (Fig. 1d). With the same assay, we dissected the determinants of the HJURP:Mis $18^{\text {core }}$ interaction, confirming that R1 (HJURP ${ }^{394-484}$ ) is sufficient to bind Mis18 ${ }^{\text {core }}$ (Fig. 1e. A summary is in Fig. 1f).

Unexpectedly, HJURP fragments encompassing R2 (e.g HJURP ${ }^{541-620}$ ) also bound Mis18 ${ }^{\text {core }}$, whereas fragments encompassing the segment between R1 and R2 (HJURP ${ }^{482-540}$ ) or the region C-terminal to R2 (HJURP ${ }^{621-748}$ ) did not (Fig. 1e, f). Binding of R2 of HJURP to the Mis $18^{\text {core }}$ complex contradicts a previous report ${ }^{8}$. Because a shorter R2 construct (HJURP $555-748$ instead of HJURP ${ }^{541-748}$ used here) had been used in the previous study $^{8}$, we compared the Mis $18^{\text {core }}$ binding proficiency of HJURP 555-748 and HJURP541-748. HJURP 541-748 bound Mis18core markedly better than MBP-HJURP ${ }^{55-748}$ (Supplementary Fig. 2a), likely explaining the different outcomes of the binding experiments. In conclusion, R1 and R2 of HJURP bind the Mis $18^{\text {core }}$ complex also in isolation and without requiring other segments of HJURP.

Sequence motifs encompassing residues 438-446 of R1 and 584592 of R2 are highly conserved (Fig. 1g), and we tested their contribution to Mis18 $8^{\text {core }}$ binding. Four-lysine mutants of repeat 1 $(4 \mathrm{~K} 1)$ or repeat $2(4 \mathrm{~K} 2)$ abrogated the interaction with Mis18 $8^{\text {core }}$ (Fig. 1h). While neither the $4 \mathrm{~K} 1$ nor the $4 \mathrm{~K} 2$ mutant disrupted binding of HJURP ${ }^{394-748}$ (which contains both repeats) to Mis $18^{\text {core }}$, combining mutations abolished the interaction (Fig. 1i). Conversely, a four-alanine mutation (4A) replacing conserved residues $407-410$ in HJURP did not affect its binding to Mis18 $8^{\text {core }}$ (Fig. 1g, h). Collectively, this shows that at least in this binding assay, at relatively high concentrations of interacting species, R1 and R2 are interchangeable towards Mis $18^{\text {core }}$ complex binding.

R2 has been proposed to promote and be sufficient for HJURP dimerization $^{33}$. To verify this claim, we applied sedimentation velocity analytical ultracentrifugation (AUC), a method of choice for accurate determination of molecular mass. In our analysis, we identified MBP-HJURP541-748 (encompassing R2) as a monomer at $5 \mu \mathrm{M}$ concentration, with no evidence of dimeric species (Supplementary Fig. 2b). A modest level of dimerization (or possibly aggregation) was only observed with the HJURP ${ }^{394-540}$ construct (encompassing R1), the bulk of which, however, was monomeric too, as previously observed ${ }^{33}$. We conclude that R1 and R2, at the relatively high concentration used in these assays, can bind independently to the Mis $18^{\text {core }}$ complex and that they are, respectively, largely or exclusively monomeric in solution in isolation from the rest of the HJURP sequence.

Correct dosage of $\mathrm{R} 1$ or $\mathrm{R} 2$ is required for CENP-A deposition. Because both R1 and R2 of HJURP support Mis18 ${ }^{\text {core }}$ complex binding, we were curious to assess if they can individually support CENP-A deposition. For this, we adapted a previously described strategy based on selective fluorescent labeling of newly deposited SNAP-tagged CENP-A in HeLa cells ${ }^{16,52}$ (Fig. 2a). Stable HeLa cell lines for tetracycline-inducible co-expression of EGFP-NLS (nuclear localization signal) or EGFP-HJURP with SNAP-tagged CENP-A (CENP-A ${ }^{\text {SNAP }}$ ) were generated by transfection of Flp-In T-REx HeLa cells ${ }^{61}$ with pcDNA5/FRT/TO derived plasmids. CENP-A ${ }^{\text {SNAP }}$ expression was adjusted by mutating internal ribosome entry site in the pcDNA5/FRT/TO plasmids. Protein expression was confirmed by western blotting (Supplementary Fig. 3a). After irreversible labeling of newly deposited CENP$\mathrm{A}^{\mathrm{SNAP}}$ with a fluorescent dye targeting the SNAP-tag (SNAP-Cell 647-SiR), we readily visualized a strong centromere signal in early G1 phase HeLa cells. In line with the essential role of HJURP in CENP-A deposition, depletion of HJURP by RNAi (Supplementary Fig. 3b) abrogated CENP-A loading (Fig. 2b).

We used this assay to test the ability of individual HJURP transgenes, expressed from the tetracycline-inducible promoter, to functionally complement the deleterious effects from depleting endogenous HJURP. EGFP-HJURPWT (wild type) strongly labeled inner kinetochores and its expression in HJURPdepleted cells resulted in almost complete recovery of CENP$\mathrm{A}^{\mathrm{SNAP}}$ deposition at inner kinetochores (Fig. 2c). The introduction of the individual $4 \mathrm{~K} 1$ mutation in $\mathrm{R} 1$ or of the $4 \mathrm{~K} 2$ mutation in $\mathrm{R} 2$, or their combination in a single construct, prevented centromere localization of HJURP and failed to support new CENP-A ${ }^{\text {SNAP }}$ incorporation at significant levels in cells depleted of endogenous HJURP (Fig. 2c-e). All three mutant constructs had strong dominant-negative effects on the ability of cells retaining wild-type HJURP (i.e., treated only with transfection reagent rather than anti-HJURP siRNA) to promote new CENPA deposition (-siRNA, Fig. 2c-e), possibly because they compete with endogenous HJURP for CENP-A or other interaction partners. Thus, although both R1 and R2 of HJURP bind the 
a

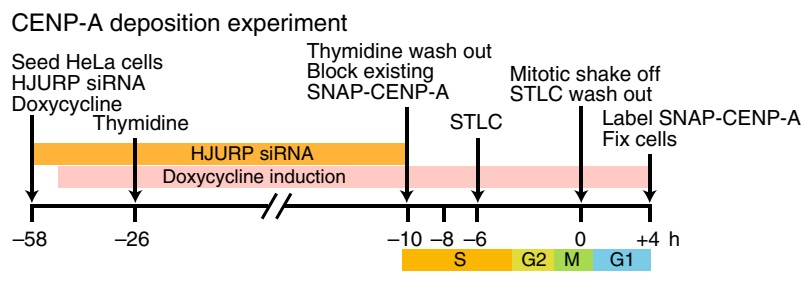

C
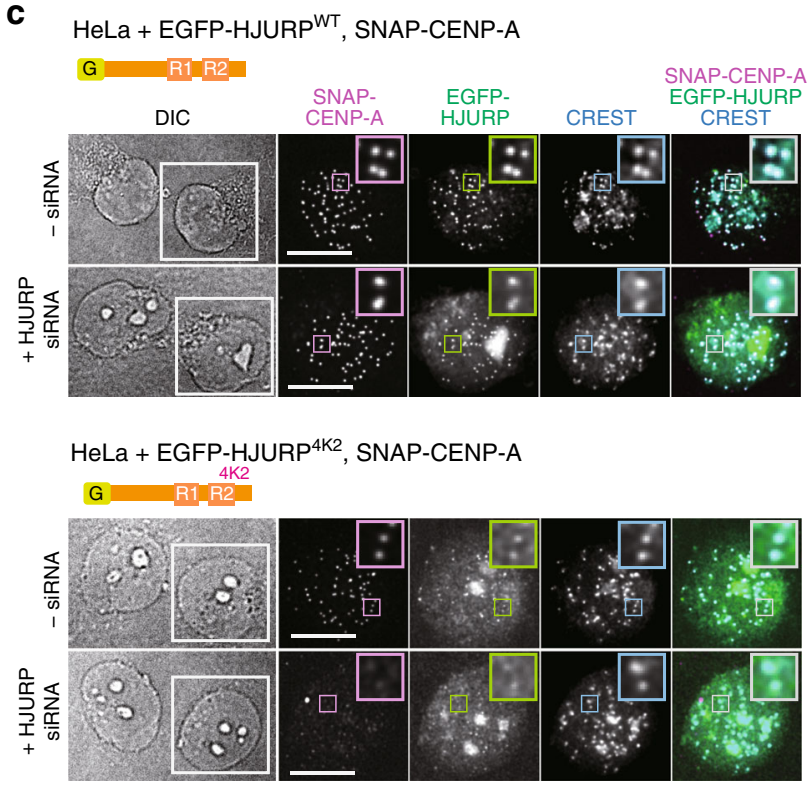

d

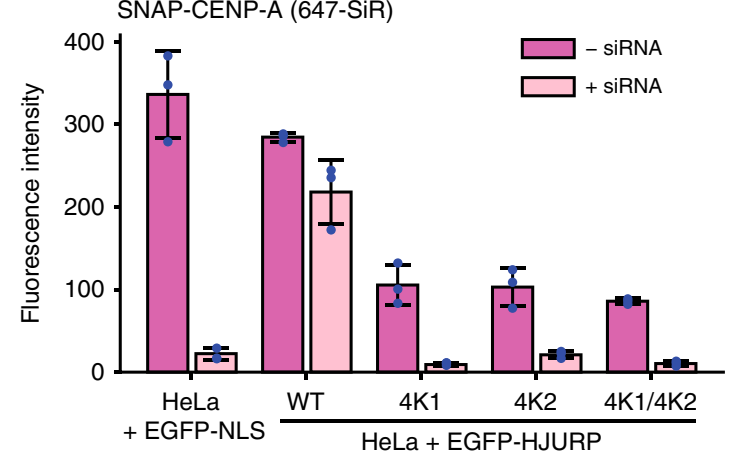

b

HeLa + EGFP-NLS, SNAP-CENP-A
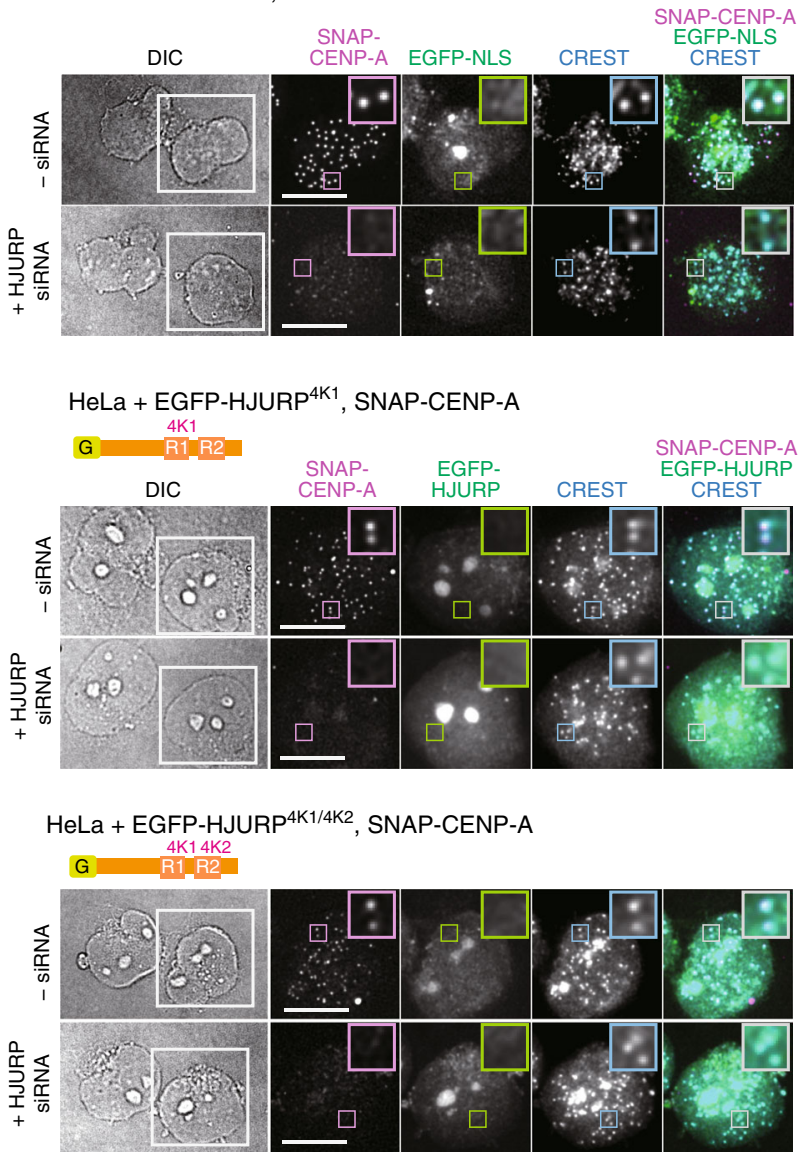

e

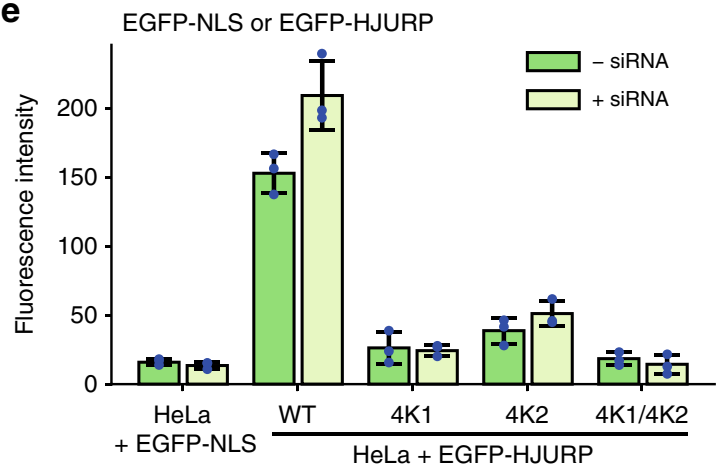

Fig. 2 Four-lysine mutations in HJURP R1 or R2 disturb HJURP localization and CENP-A deposition. a Schematic of the CENP-A deposition experiment for testing functionality of HJURP variants. SNAP-Cell 647-SiR was used to label newly produced SNAP-CENP-A at the time point $+4 \mathrm{~h}$. $\mathbf{b}, \mathbf{c}$ Representative images showing SNAP-CENP-A fluorescence and EGFP-NLS or EGFP-HJURP variants in fixed HeLa cells treated as described in panel a. Centromeres were visualized with CREST sera. Control cells were treated with transfection reagent (Lipofectamine RNAiMAX) in the absence of HJURP siRNA. DIC, differential interference contrast. One side of the white square in the DIC panel represents $20 \mu \mathrm{m}$. White scale bars indicate $10 \mu \mathrm{m}$. All cell biological experiments in this paper were repeated at least three times. d Quantification of the centromere fluorescence intensity of SNAP-CENP-A. Centromere spots were detected using the images of CREST channel and were applied to the images of other data channels. In each experiment, a mean value of centromere fluorescence intensity was obtained from at least 340 centromere spots from at least 20 early G1 cells. The highest $10 \%$ and the lowest $10 \%$ intensity values were considered outliers and excluded. The bar graph represents mean values from the three replicate experiments (blue dots indicate the mean values from each experiment). Error bars indicate standard deviations. The ways of quantification and representation described here apply to other figures displaying experiments in HeLa cells. e Quantification of the centromere fluorescence intensity of EGFP signal. Source data are provided as a Source Data file

Mis18 $8^{\text {core }}$ complex in a biochemical assay, they are both required in a cellular assay probing HJURP centromere recruitment and CENP-A deposition.

The strong defect on CENP-A deposition observed with individual mutations in the R1 or R2 motifs may reflect functional specialization, or, alternatively, reduced dosage of functionally equivalent regions. The in vitro characterization in Fig. 1 supports the second hypothesis, but we sought formal proof by asking if CENP-A deposition was rescued by HJURP constructs harboring tandem copies of the same repeat. HJURP constructs where R1 or 
a

HeLa + EGFP-HJURP ${ }^{\triangle 394-532}$, SNAP-CENP-A
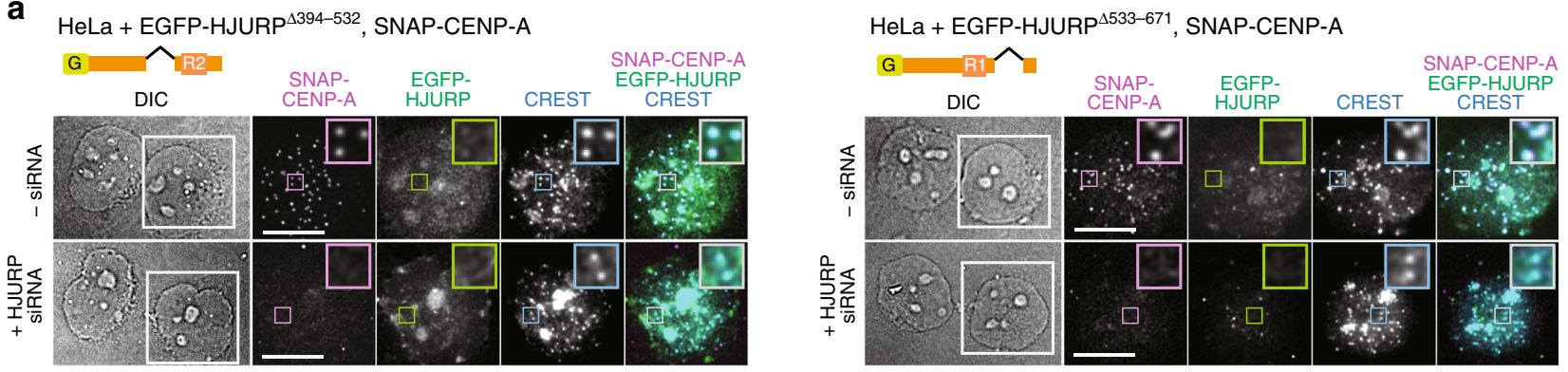

HeLa + EGFP-HJURPR1-R1, SNAP-CENP-A

G

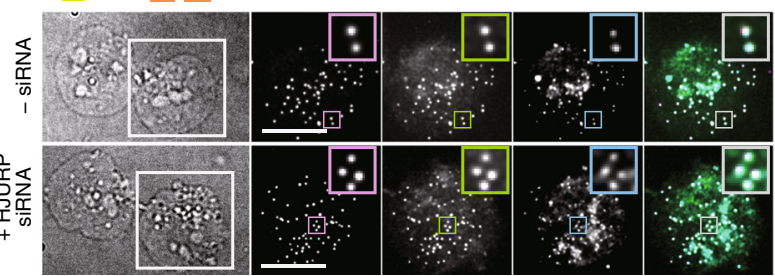

HeLa + EGFP-HJURPR2-R2, SNAP-CENP-A

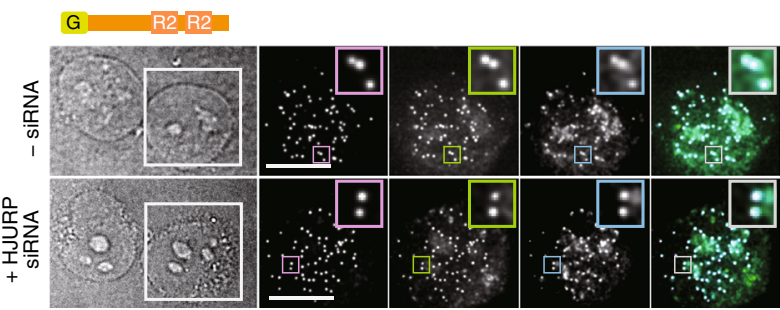

b

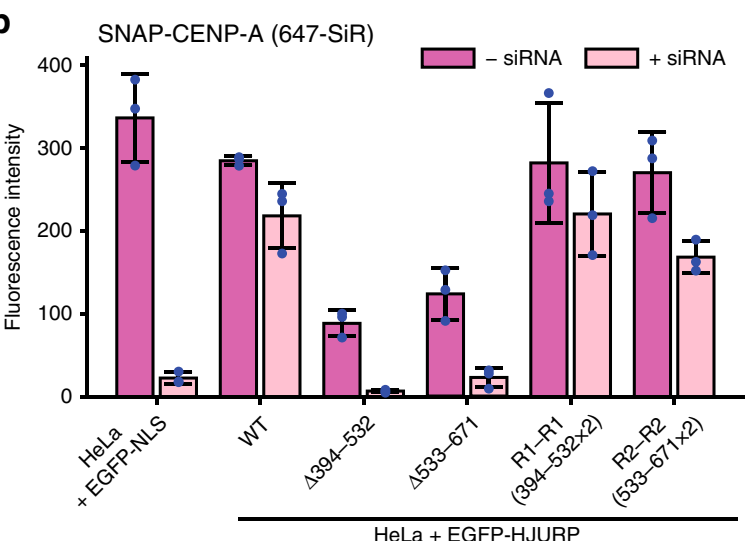

C

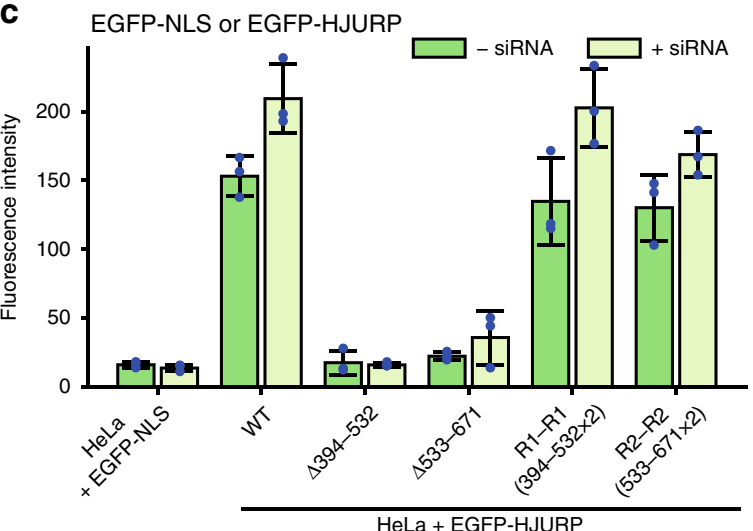

d

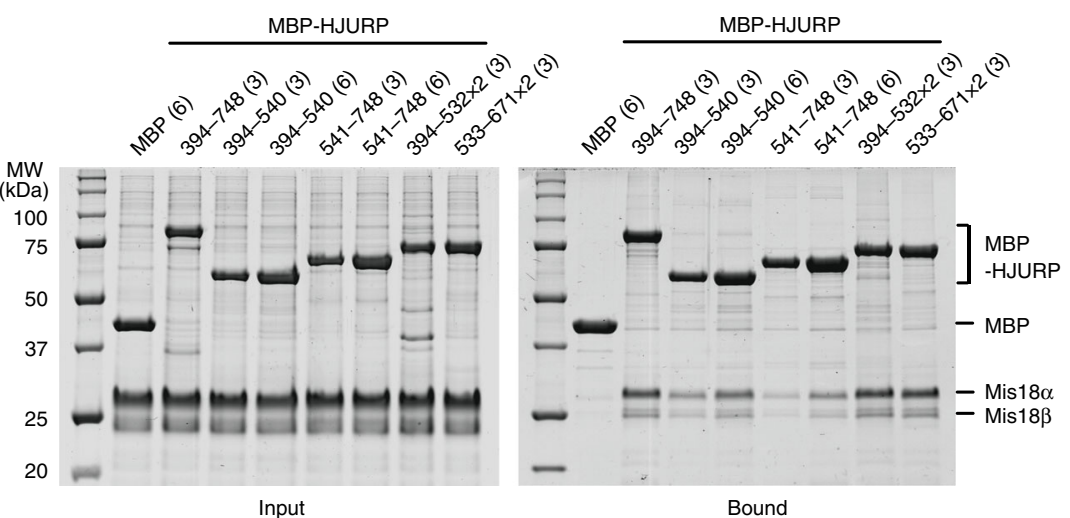

Fig. 3 Tandem repeats of HJURP R1 or R2 rescue the localization of HJURP and CENP-A deposition. a Representative images showing the fluorescence of SNAP-CENP-A and EGFP-HJURP variants in fixed HeLa cells treated as described in Fig. 2a. White scale bars indicate $10 \mu \mathrm{m}$. $\mathbf{b}$, c Quantification of the centromere fluorescence intensity of SNAP-CENP-A or EGFP-HJURP variants. The bar graphs represent mean values from three replicate experiments (blue dots indicate the mean values from each experiment). Error bars indicate standard deviations. d SDS-PAGE results of amylose-resin pull-down assays showing the increase of HJURP binding to Mis18core when tandem repeats of R1 and R2 were used. The numbers in the parenthesis indicate the concentrations $(\mu M)$ of the proteins used in the assays. Source data are provided as a Source Data file

R2 had been deleted (HJURP $\triangle 394-532$ or HJURP $4533-671$, respectively) failed to localize to kinetochores, were unable to load new CENP-A $\mathrm{A}^{\mathrm{SNAP}}$ onto centromeres, and resulted in a strong dominant-negative effect on CENP-A deposition in presence of endogenous HJURP (Fig. 3a-c), precisely as already observed with the $4 \mathrm{~K}$ mutants. In contrast, constructs harboring identical tandem repeats (HJURPR1-R1 or $\mathrm{HJURP}^{\mathrm{R} 2-\mathrm{R} 2}$ ) localized robustly to kinetochores and rescued CENP-A deposition to levels similar to those achieved by expression of HJURPWT. In pull-down assays with recombinant proteins in vitro, HJURP constructs consisting of 
tandem R1 or R2 repeats showed increased affinity for Mis $18^{\text {core }}$ than constructs with single R1 or R2 repeats (Fig. 3d). Collectively, these results indicate that R1 and R2 are at least largely functionally redundant, and that their appropriate dosage is crucial. A single HJURP repeat is sufficient for the interaction with Mis18 $8^{\text {core }}$ at the relatively high concentrations of the in vitro assays, but insufficient for kinetochore recruitment and CENP-A loading at the lower cellular concentrations, making the presence of two repeats necessary, largely regardless of their identity. In combination with the demonstration that both $\mathrm{R} 1$ and $\mathrm{R} 2$ are monomeric, our results do not support a role of R2 dimerization in HJURP function ${ }^{33}$.

The Mis18a N-terminal region modulates HJURP binding. Next, we tried to identify molecular determinants of the interaction of Mis $18^{\text {core }}$ with HJURP. We have shown previously that the Mis $18^{\text {core }}$ complex binds tightly to residues $1-60$ of M18BP1 $\left(\mathrm{M} 18 \mathrm{BP} 1^{1-60}\right)$, and less tightly to residues $61-140$ $\left(\mathrm{M} 18 \mathrm{BP} 1^{61-140}\right)^{52}$. In agreement with the previous results, Mis $18^{\text {core }}$ bound immobilized MBP-M18BP1 $1^{1-60}$ tightly in solid phase binding assays (Fig. 4a). Mis $18^{\text {core }}$ also bound MBPM18BP161-140, but apparently with lower binding affinity, and at levels that were comparable to those obtained with immobilized single-repeat baits MBP-HJURP ${ }^{394-540}$ and MBP-HJURP $541-748$ (Fig. 4a).

The Mis $18^{\text {core }}$ complex was originally characterized as an oligomer with a proposed 2:2 stoichiometry of Mis18a and Mis $18 \beta^{8,62}$, but additional work demonstrated a 4:2 Mis18a: Mis18 $\beta$ hexamer ${ }^{52,54}$. Crucial to the establishment of this stoichiometry are the assembly of a 3-helical bundle of the Cterminal helices and the dimerization of the Yippee domains ${ }^{52,54,62}$. The 4:2 Mis $18^{\text {core }}$ hexamer interacts with the $\mathrm{N}$-terminal segments of two protomers of M18BP1, generating a 4:2:2 assembly 22,39,52,54.

Deletion of the predicted C-terminal helices $(\mathrm{CH}$, Fig. 1a) affects the oligomerization state of Mis $18^{\text {core }}$, resulting in simple Mis18a:Mis18 $\beta$ dimers, held together by the Yippee domains, which remain able to bind $\mathrm{M} 18 \mathrm{BP} 1^{52,54}$. On the contrary, a $\mathrm{CH}$ deleted Mis18 $8^{\text {core }}$ (Mis18a: ${ }^{1-191}$ Mis $18 \beta^{1-189}$ ) decreased or even abrogated binding to all four immobilized MBP bait constructs (Fig. 4b), indicating that structural integrity of the complex or the $\mathrm{CH}$ regions themselves (or both) are required for the interaction (as discussed below).

In an unanticipated outcome of these experiments, we observed that deletion of the N-terminal regions of Mis18a and Mis18 $\beta$ (Mis18 $\alpha:^{78-233}$ Mis18 $\beta^{65-229}$ ) did not affect its hexameric state (Supplementary Fig. 4a) but strongly promoted binding to MBP-HJURP ${ }^{394-540}$ and MBP-HJURP $541-748$, to levels that were as robust as those observed with $\mathrm{M} 18 \mathrm{BP} 1^{1-60}$ (Fig. 4c). This effect was recapitulated by deleting the N-terminal tail of the Mis $18 \alpha$ subunit (Mis18a ${ }^{78-233}:$ Mis $18 \beta^{1-229}$, Fig. 4d), but not the Nterminal tail of the Mis18 $\beta$ subunit (Mis18 $\alpha^{1-233}:$ Mis18 $\beta^{65-229}$ ) (Fig. 4e). The $\mathrm{CH}$ regions of Mis18 $\alpha$ and Mis18 $\beta$ were necessary for HJURP binding also when combined with deletions of the $\mathrm{N}$ terminal regions (Mis18 $a^{78-191}:$ Mis $18 \beta^{73-189}$ ) (Fig. 4f). Of note, this effect of Mis18 $\alpha^{78-233}$ :Mis18 $\beta^{65-229}$ was specific for the R1 or R2 regions of HJURP, because binding to MBP-M18BP1 ${ }^{1-60}$ or MBP-M18BP $1^{61-140}$ remained strong or weak, respectively, even with the longest deletions tested (Fig. $4 c-e$ ), confirming that the $\mathrm{N}$-terminal regions of the Mis18 complex subunits are not strictly necessary for M18BP1 binding 52 .

A strongly conserved motif between residues 26 and 54, also predicted to adopt $\alpha$-helical conformation, is present in the $\mathrm{N}$ terminal region of mammalian Mis18a sequences (Fig. 4g, Supplementary Fig. 4b). We asked if this region of Mis $18 a$ contributes to the observed modulation of the binding affinity for
HJURP. To test this, we created various deletions of the Mis18a $\mathrm{N}$-terminal region that either excluded or included the predicted $a$-helix within the conserved motif. The deletion mutants

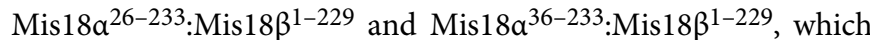
preserve the predicted $\alpha$-helix, did not bind the MBP control but bound the HJURP single-repeat baits MBP-HJURP ${ }^{394-540}$ and MBP-HJURP541-748 with the relatively low apparent affinity already observed with full-length Mis $18^{\text {core }}$ (Fig. 4h-j). Conversely, additional deletions that removed the predicted $\alpha$-helix

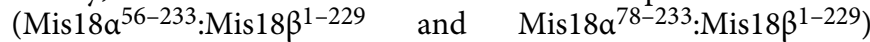
strongly increased the apparent binding affinity for the HJURP repeats (Fig. $4 \mathrm{~h}-\mathrm{j}$ ). The same N-terminal deletions of the Mis18 complex did not show progressively increased binding affinity for the M18BP1 ${ }^{61-140}$ construct (Fig. 4k; in fact, the apparent binding affinity appeared to decrease slightly with longer deletions, revealing a marginal effect in binding) but were equally good binders of the M18BP1 $1^{1-60}$ construct (Supplementary Fig. 4c). We conclude that the effects of the $\mathrm{N}$-terminal deletions are HJURP specific.

The results of these binding assays, which are collectively summarized in Fig. 4l, predict that the Mis18a N-terminal tail might be dispensable for centromere recruitment of HJURP and new CENP-A deposition. To test this, we depleted Mis18a by RNAi interference (Supplementary Fig. 5a, b). As expected, the Mis18 complex was necessary for CENP-A SNAP deposition and its depletion prevented new CENP-ASNAP deposition onto centromeres in early G1 (Supplementary Fig. 5c). This deficiency was rescued by expression of Mis18aWT or Mis18a $\alpha^{56-233}$ transgenes (Supplementary Fig. 5b, c, quantified in panel D), indicating that the N-terminal region of Mis18 $\alpha$ is not required for the loading reaction. In fact, Mis18 $a^{56-233}$ decorated centromeres even more brightly than Mis $18 \alpha^{\mathrm{WT}}$, and complemented more effectively the depletion of endogenous Mis18a, in agreement with the results in vitro.

HJURP and Mis18 subunits form a stoichiometric complex. Binding of HJURP has been shown to cause dissociation of a Mis $18^{\text {core }}$ tetramer into dimers and release of its subunits from centromeres $^{8}$. Because in our previous studies we characterized the Mis18a:Mis18 $\beta$ assembly for containing a hexameric Mis18core and for being very stable in vitro ${ }^{52,54}$, we wanted to verify whether HJURP caused dissociation of the Mis18 core complex. For this, we performed size-exclusion chromatography (SEC) analyses, where proteins are separated based on their size and shape. As expected, MBP-HJURP ${ }^{394-748}$, which encompasses both the R1 and R2 regions, bound full-length Mis18 ${ }^{\text {core }}$ (Fig. 5a). Shorter HJURP segments encompassing only the R1 or R2 regions (MBP-HJURP ${ }^{394-540}$, or MBP-HJURP ${ }^{541-748}$ ), however, showed weaker binding to Mis $18^{\text {core }}$ (Fig. 5b, c), in agreement with the solid phase binding assays in Fig. 1. Nevertheless, the same HJURP constructs bound strongly to the Mis $18 a^{56-233}$ : Mis $18 \beta^{1-229}$ HJURP-super-binder complex (Fig. 5d-f). There was no evidence that the interaction of HJURP causes dissociation of the Mis $18^{\text {core }}$ complex as previously reported ${ }^{8}$.

To identify the copy number of HJURP binding to the Mis $18^{\text {core }}$ complex, we purified Mis18 $\alpha^{56-233}$ :Mis18 $\beta^{1-229}:$ HJURP $394-748$ and Mis18 $\alpha^{56-233}$ :Mis18$\beta^{1-229}:$ MBP-HJURP ${ }^{394-748}$ complexes by SEC and analyzed them by sedimentation velocity AUC (Fig. $5 \mathrm{~g}, \mathrm{~h}$, Supplementary Fig. 6a-c). The Mis18 $a^{56-233}$ :Mis18 $\beta^{1-229}$ HJURPsuper-binder retains the typical 4:2 stoichiometry of the full-length Mis $18^{\text {core }}$ complex ${ }^{52,54}$, indicating that deletion of the Mis18a Nterminal region in the HJURP-super-binder does not affect the stoichiometric ratios of the complex. The observed molecular weights of Mis18 $\alpha^{56-233}:$ Mis18 $\beta^{1-229}: H J U R P^{394-748}$ and

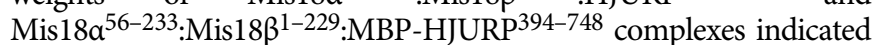


a

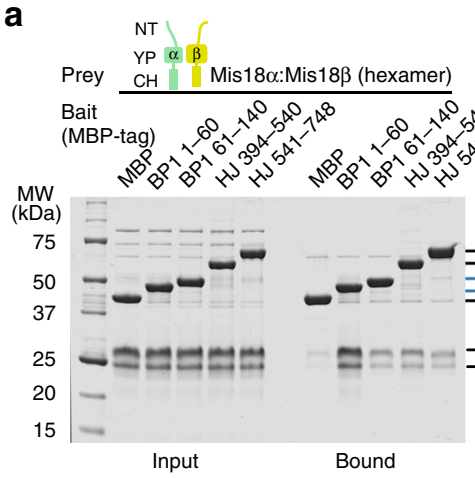

d

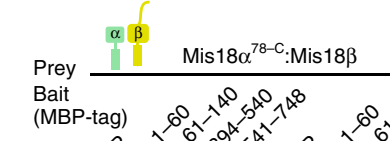

b

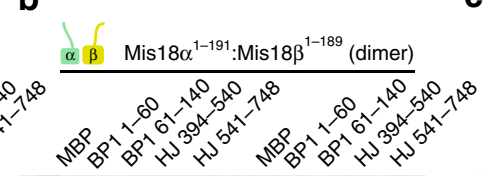

c

${ }^{\alpha \beta}{ }^{\beta}$ Mis $18 \alpha^{78-C}:$ Mis $18 \beta^{65-C}$ (hexamer)

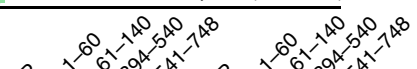

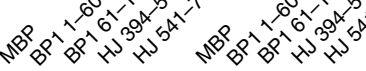

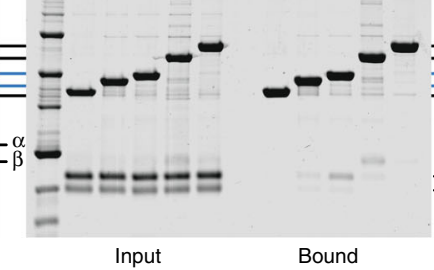

e
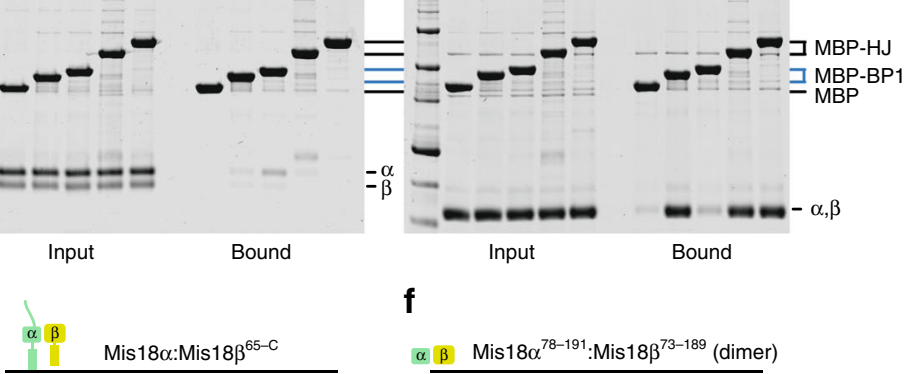

f

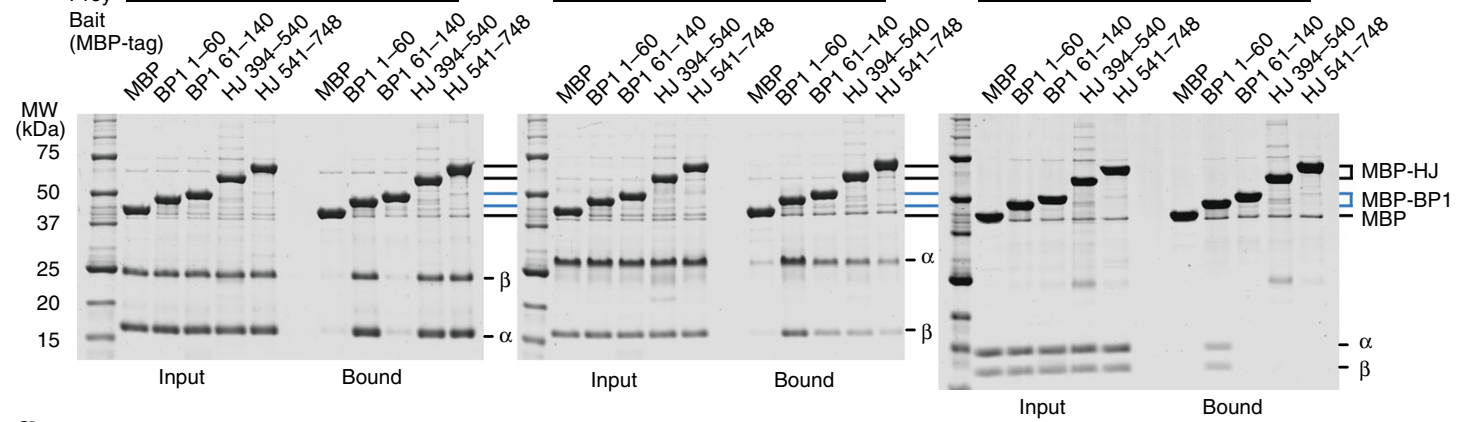

g
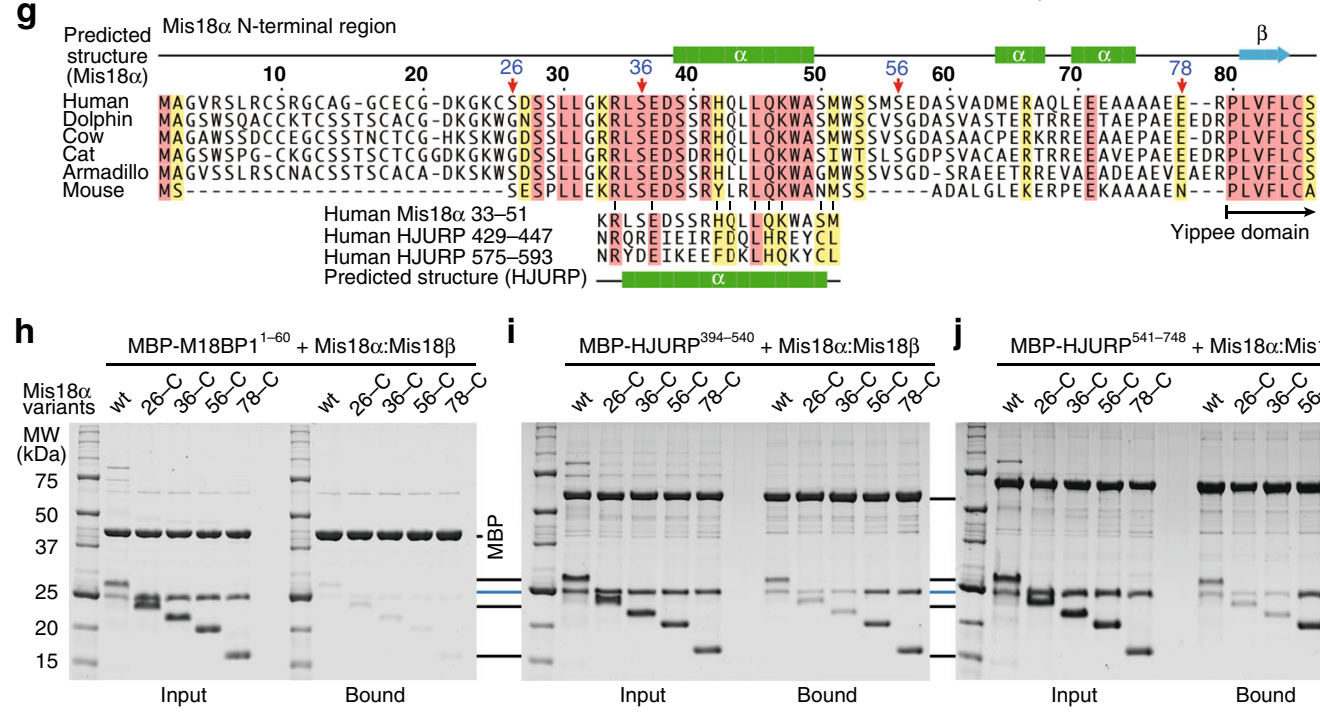

$\frac{\text { MBP-HJURP }}{3^{541-748}+\text { Mis180:Mis } 18 \beta}$

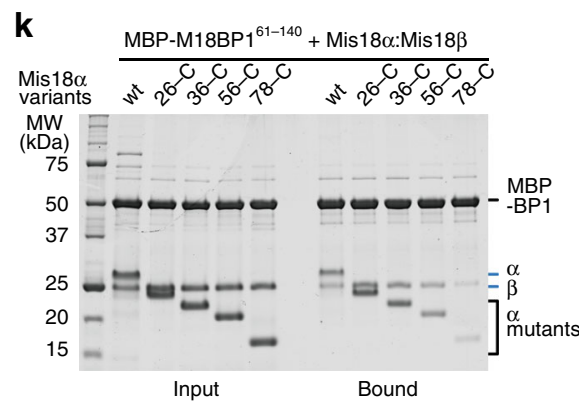

I

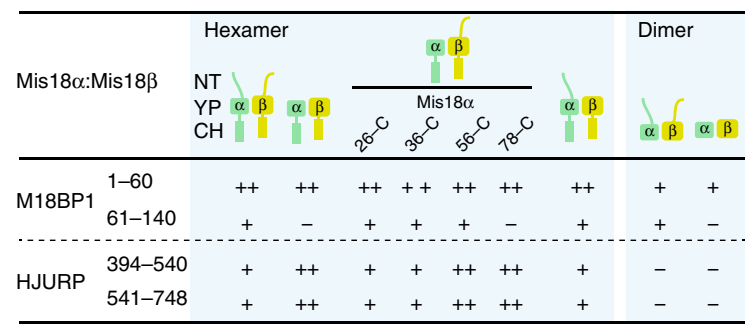

binding of only one copy of HJURP $394-748$ to Mis18a ${ }^{56-233}$ : Mis $18 \beta^{1-229}$ complex (Fig. 5g, h, Supplementary Fig. 6a-c).

Next, we asked if full-length Mis $18^{\text {core }}$ or Mis18a $a^{56-233}$ : Mis18 $\beta^{1-229}$, when combined with MBP-M18BP1-228 and MBP-HJURP ${ }^{394-748}$, gave rise to complexes comprising all four subunit types. MBP fusion constructs encompassing different segments of the bi-partite Mis18 core binding site in the M18BP1 $\mathrm{N}$-terminal region (MBP-M18BP1 ${ }^{1-140}$, MBP-M18BP1 $1^{1-60}$, and MBP-M18BP $1^{61-140}$ ) were incubated with Mis $18^{\text {core }}$ or Mis18 $\alpha^{56-233}:$ Mis $18 \beta^{1-229}$. We then asked if addition of HJURP ${ }^{394-748}$ (containing the R1 and R2 regions of HJURP) disrupted this complex. To increase the solubility of 
Fig. 4 Systematic interaction analysis reveals binding mechanism of HJURP on Mis18core. a-f Amylose-resin pull-down assays were performed using MBPtagged M18BP11-60, M18BP161-140, HJURP394-540, and HJURP541-748 with different constructs of Mis18core. Binding buffer B containing $15 \mathrm{mM}$ HEPES $\mathrm{pH}$ 7.5, $150 \mathrm{mM} \mathrm{NaCl}, 1 \mathrm{mM}$ TCEP, and $0.01 \%$ Tween-20 was used for the pull-down assays presented in panel $\mathbf{b}$ and $\mathbf{f}$. Binding buffer $A$ was used for other pull-down assays. $\mathbf{g}$ Amino-acid sequence alignment showing the $\mathrm{N}$-terminal region of mammalian Mis18 $\alpha$. The sequence similarity among highly conserved regions in HJURP R1, R2 and the N-terminus of Mis18 $\alpha$ is shown. Regions predicted to form $\alpha$-helices are indicated by green bars. h-k Amyloseresin pull-down assays were performed to identify the residues of Mis18 $\alpha$ that modulate the binding of HJURP to Mis 18 core. I A table summarizing the pulldown results presented here and in Supplementary Fig. 4c. single plus and double plus indicate weak and strong interactions, respectively

HJURP $394-748$, we fused it to a mutant MBP that had been rendered unable to bind amylose (defined as MBPKR, and containing the two previously reported mutations E111K and W230R ${ }^{63}$ ). MBPKR-HJURP ${ }^{394-748}$ did not bind to the MBP control or the MBP-M18BP1 baits in the absence of Mis $18^{\text {core }}$, but it bound robustly when Mis $18^{\text {core }}$ was supplemented, indicating that HJURP and M18BP1 bind concomitantly to the Mis18 complex (Fig. 6a, b). We corroborated this conclusion with SEC analyses. MBP-M18BP1 $1^{1-228}$ readily bound full-length Mis $18^{\text {core }}$ or the Mis18 $\alpha^{56-233}:$ Mis $18 \beta^{1-229}$ construct as we reported previsouly ${ }^{52}$, but did not bind MBP-HJURP ${ }^{394-748}$ (Fig. 6c), indicating that M18BP1 and HJURP do not interact directly. When the Mis $18^{\text {core }}$ was added, a complex containing all four subunits was observed, without evidence of Mis18 core dissociation (Fig. 6d, e), thus demonstrating that M18BP1, Mis18a, Mis18 $\beta$, and HJURP can form a single stable complex.

As a further demonstration of this result, we resorted again to sedimentation velocity AUC. The complex of the Mis $18 a^{56-233}$ : Mis18 $\beta^{1-229}$ HJURP-super-binder with FAM MBP-M18BP1 1-228 shows the familiar 4:2:2 stoichiometry ${ }^{52,54}$ (Fig. 6f, g, Supplementary Fig. 6d, e). Next, we added two or four equivalents of MBP-HJURP ${ }^{394-748}$ to the $4: 2: 2$ Mis18 $^{56-233}:$ Mis18 $\beta^{1-229}$ :MBP${ }^{F A M}{ }_{M 18 B P 1} 1^{1-228}$ assembly and assessed the molecular mass of the resulting complex. This unequivocally showed that only one equivalent of MBP-HJURP ${ }^{394-748}$ is incorporated in the $4: 2: 2$ complex, giving rise to a 4:2:2:1 stoichiometry, without dissociation of Mis18a from Mis18 $\beta$ (Fig. 6f, g, Supplementary Fig. 6d, e).

HJURP-binding sites on Mis18. In a previous study, the Cterminal regions of Mis18 $\alpha$ and Mis18 $\beta$ were proposed to be sufficient to recruit HJURP to an ectopic chromosome locus and for an interaction in vitro with 1:1:1 stoichiometry ${ }^{8}$. We reexamined these previous findings in light of our new observations that both the R1 and the R2 repeat of HJURP interact with the Mis $18^{\text {core }}$, and that the $\mathrm{CH}$ regions form trimers rather than dimers $^{52,54}$. We used amber-codon suppression methodology ${ }^{64}$ to introduce, in different positions of the $\mathrm{R} 1$ or $\mathrm{R} 2$ regions of HJURP, unnatural amino-acids with photo-activatable cross-linker groups, $p$-benzoyl-L-phenylalanine (Bpa) and 3 '-azibutyl- $N$ carbamoyl-lysine (AbK) (Fig. 7a). MBP-HJURP394-540 or MBPHJURP $541-748$ containing either $\mathrm{Bpa}$ or $\mathrm{AbK}$ at 12 different positions (indicated in Fig. $7 \mathrm{~b}$ ) of the R1 or R2 segments were combined with Mis18 $\alpha^{56-233}:$ Mis $18 \beta^{1-229}$, and the cross-linking (XL) reaction was activated with $365 \mathrm{~nm}$ ultraviolet (UV) light on the resulting complex (shown schematically Fig. 7c, left). Prominent high-molecular weight bands appeared after UV exposure, indicating that MBP-HJURP constructs containing Bpa or AbK had reacted with Mis18 $\alpha$ and Mis18 $\beta$ (Supplementary Fig. 7a). Cross-linked products were further purified using $\mathrm{Ni}^{2+}$ affinity resin, washed with urea buffer, and subjected to proteolysis and mass spectrometry (MS) analysis. We identified many cross-links of the Bpa- or AbK-incorporated HJURP fragments with Mis $18 \alpha$ or Mis $18 \beta$ (Fig. $7 \mathrm{~d}-\mathrm{f}$ ). The vast majority of residues targeted by Bpa or AbK mapped to the predicted 3-helical bundle encompassing the $\mathrm{CH}$ regions of Mis18a or Mis18 $\beta$, in line with previous findings implicating these regions in HJURP binding ${ }^{8}$. Introduction of the cross-linkers in the R1 or the R2 segments resulted in similar patterns of cross-links.

These results indicate that $\mathrm{R} 1$ and $\mathrm{R} 2$ each bind one of the two predicted $\mathrm{CH}$ trimers in the Mis $18^{\text {core }}$ complex (Fig. $7 \mathrm{c}$, right), a finding that is consistent with the functional equivalence of the R1 and R2 fragments demonstrated above. A parsimonious expectation based on the 4:2 stoichiometry and mode of intersubunit interaction is that the Mis $18^{\text {core }}$ complex is two-fold symmetric. Thus, we expect the interactions of R1 and R2 with the $\mathrm{CH}$ domains to be semi-equivalent. In Fig. 4, we showed that the $\mathrm{CH}$ domains are necessary for Mis $18^{\text {core }}$ to bind HJURP. To assess if the $\mathrm{CH}$ domains are sufficient to bind HJURP, we tested binding of immobilized HJURP ${ }^{394-748}$ (which covers the R1 and R2 repeats, Fig. 1f) to trimeric constructs only encompassing the $\mathrm{CH}$ domains of Mis $18 \alpha \beta^{52}$. To mimic the stoichiometry of $\mathrm{CH}$ domains in the Mis $18^{\text {core }}$ complex, we fused GST in frame with Mis $18 \beta^{175-229}$ to cause dimerization of the trimers ${ }^{65,66}$. Nevertheless, no binding of the Mis18 $\mathrm{CH}$ regions to immobilized HJURP ${ }^{394-748}$ was observed (Supplementary Fig. 7b), indicating that in addition to the $\mathrm{CH}$ domains, contacts with the rest of the Mis18 complex increase the overall binding affinity for HJURP.

A separation of function mutant prevents HJURP recruitment. We used program CCBuilder $2.0^{67}$ to model the interaction of the $\mathrm{CH}$ helices in their 2:1 Mis18a:Mis18 $\beta$ stoichiometry and thus visualize their 3-dimensional organization. At this moment, there is no published result defining the orientation of $\alpha$-helices in the $\mathrm{CH}$ trimer. Judging from the mapping of the cross-links obtained, the binding site for HJURP R1 and R2 is formed by one $\mathrm{CH}$ helix of Mis $18 \alpha$ and one of Mis $18 \beta$ in a parallel configuration (Fig. 7e). The model also suggests that the third predicted helix of Mis18a does not affect the HJURP-binding pocket. We modeled it in a parallel configuration with the other two helices, but recognize that it might assemble in an anti-parallel configuration without consequences for our conclusions. Residues that were targeted by $\mathrm{Bpa}$ and $\mathrm{AbK}$ in the $\mathrm{R} 1$ or $\mathrm{R} 2$ repeats had very similar footprints on this model (Fig. 7f, g).

The emerging surface formed by the parallel $\mathrm{CH}$ helices of Mis18 $\alpha$ and Mis18 $\beta$ contains various conserved residues,

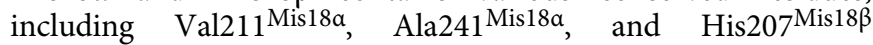
(Fig. 8a). We hypothesized therefore that this region is implicated in the interaction with $\mathrm{R} 1$ and $\mathrm{R} 2$. To test this, we created individual point mutations at $\mathrm{Val} 211^{\mathrm{Mis} 18 \alpha}$, Ala214 ${ }^{\mathrm{Mis} 18 \alpha}$, and His207 Mis18 ${ }^{\text {. Met214 }}{ }^{\text {Mis } 18} \beta$ was also tested because it was crosslinked to both F584BpaHJURP and Y591BpaHJURP. The V211D Mis18a mutant was almost completely impaired in its binding to MBP-HJURP $394-748$ (Fig. 8b). Another mutant, A214D Mis18a, was also partly impaired, whereas two additional mutants $\mathrm{H} 207 \mathrm{~A}^{\mathrm{Mis} 18} \beta$ and M214D ${ }^{\text {Mis } 18} \beta$ did not seem to alter the affinity for HJURP. Importantly, the penetrant V211D Mis18a mutant appeared to retain all its binding affinity for M18BP1 (Fig. 8c). Thus, V211D $\mathrm{D}^{\mathrm{Mis} 18 \alpha}$ is a separation-of-function mutant that selectively impairs the interaction of the Mis 18 complex with HJURP but does not impair the interaction of the Mis 18 complex with M18BP1. Importantly, the V211D Mis18a mutation did not 

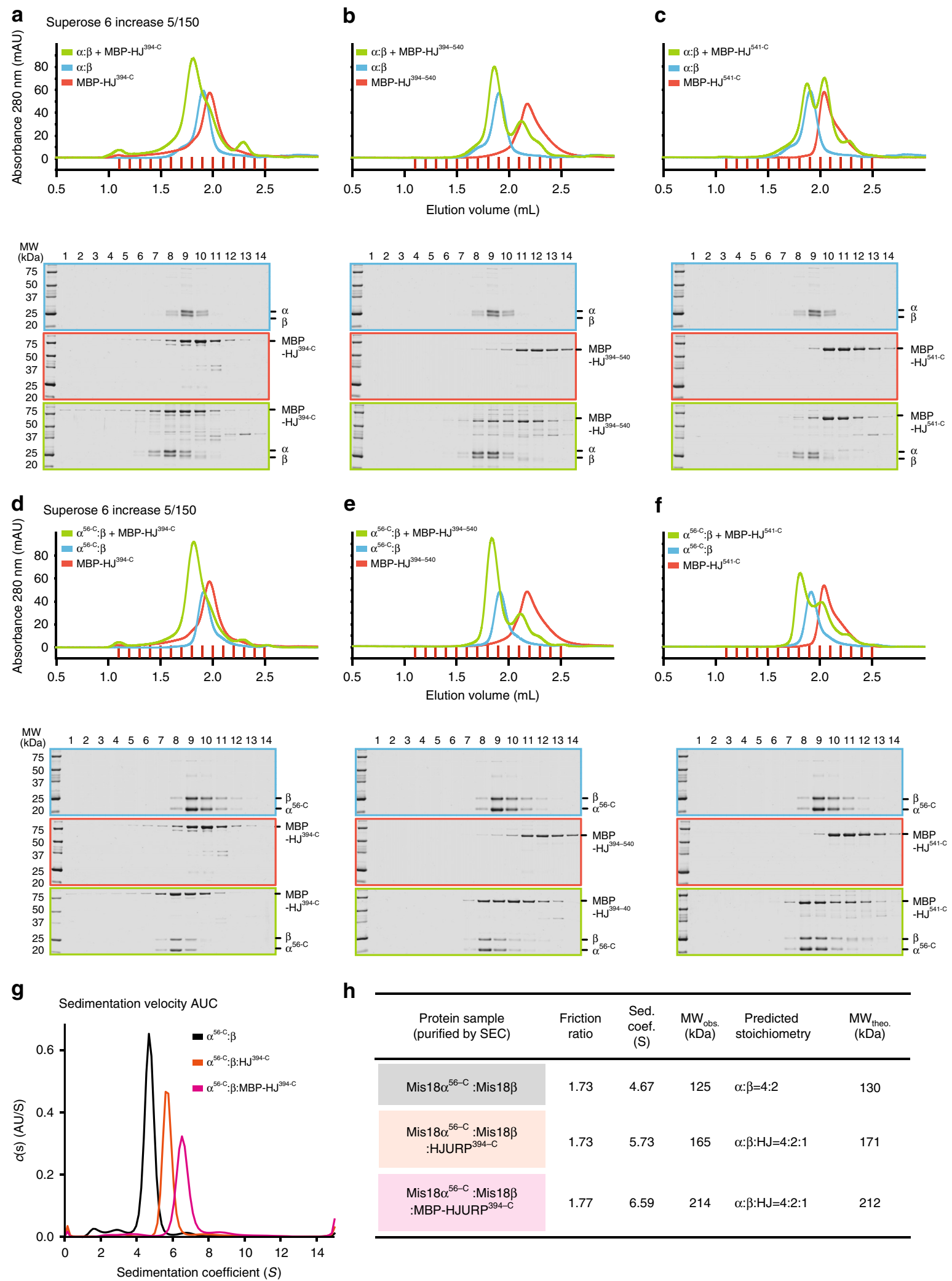

Fig. 5 Mis18core forms stable complex with only one copy of HJURP. a-f Analytical SEC experiments were performed to confirm that HJURP fragments bind full-length Mis18core or Mis18 $\alpha^{56-C}:$ Mis18 $\beta$ without dissociation of these complexes. SDS-PAGE gels were stained with CBB. $\mathbf{g}$ Sedimentation coefficient distributions obtained from the sedimentation velocity AUC experiments using the purified samples described in Supplementary Fig. 6a, b. Data profiles used for curve-fitting analyses are shown in Supplementary Fig. $6 \mathrm{c}$. h A table showing the values obtained from the AUC experiments in panel $\mathbf{g}$. Sed. coef. sedimentation coefficient, $\mathrm{MW}_{\text {obs. }}$ observed molecular weight, $\mathrm{MW}_{\text {theo. }}$ theoretical molecular weight 
a

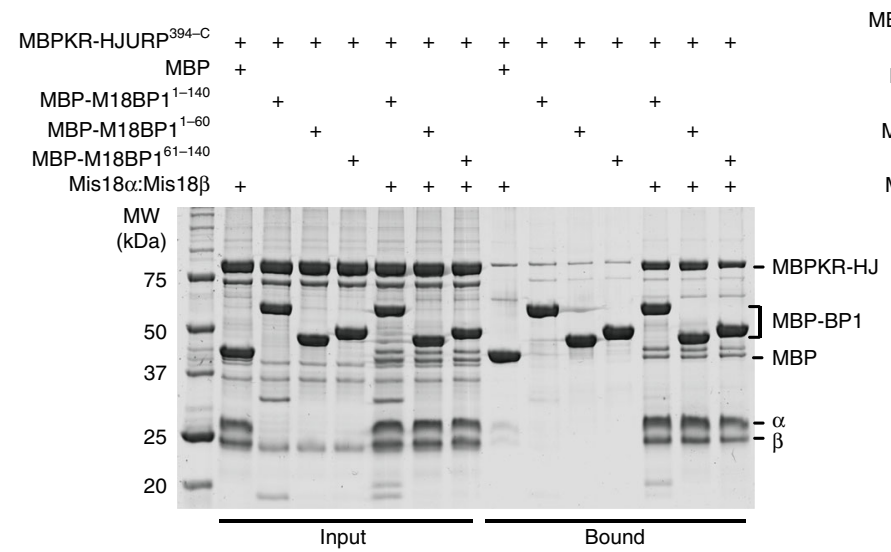

b

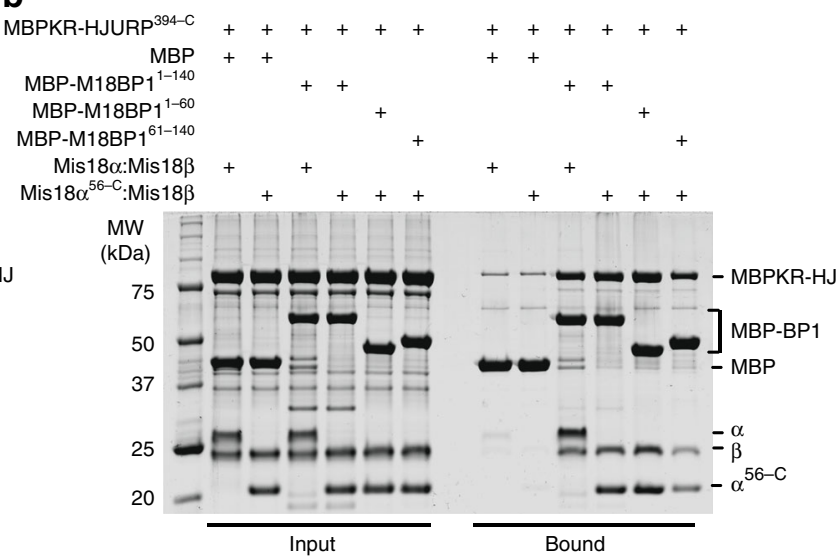

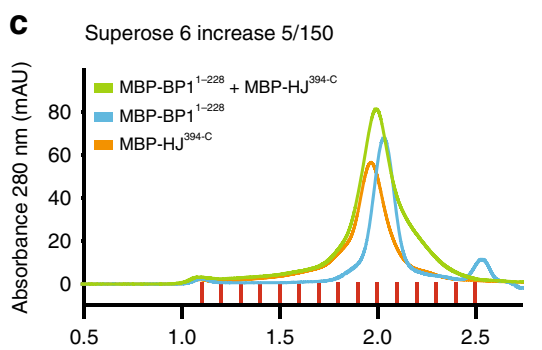

d

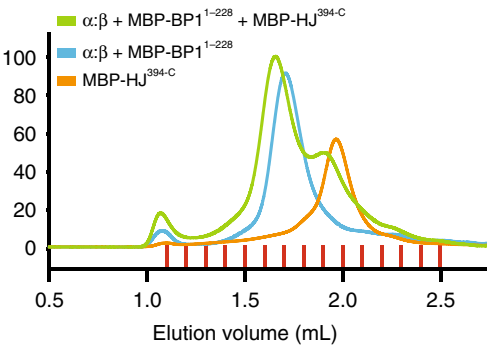

e
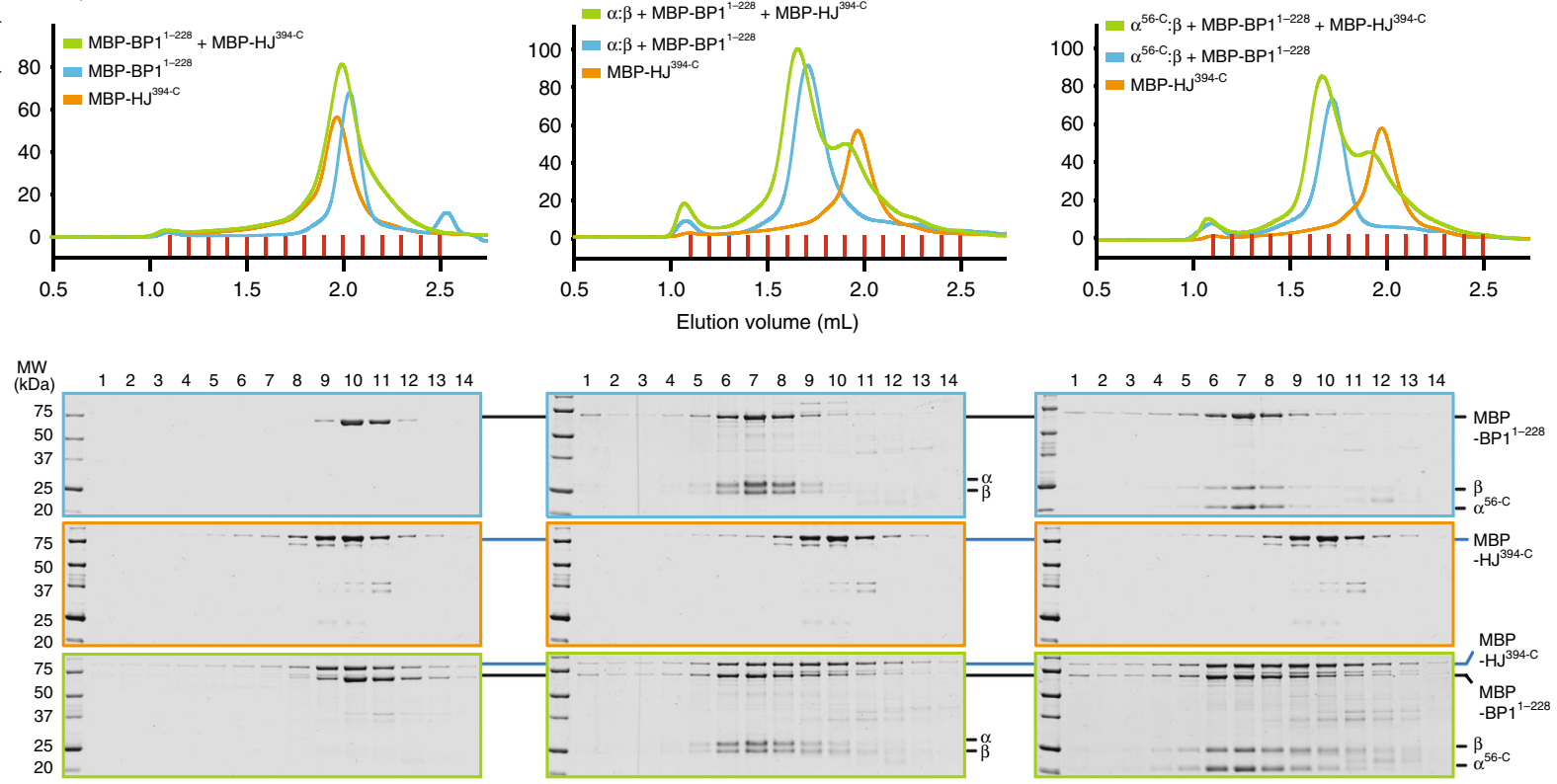

$\mathbf{f}$

Sedimentation velocity AUC

g

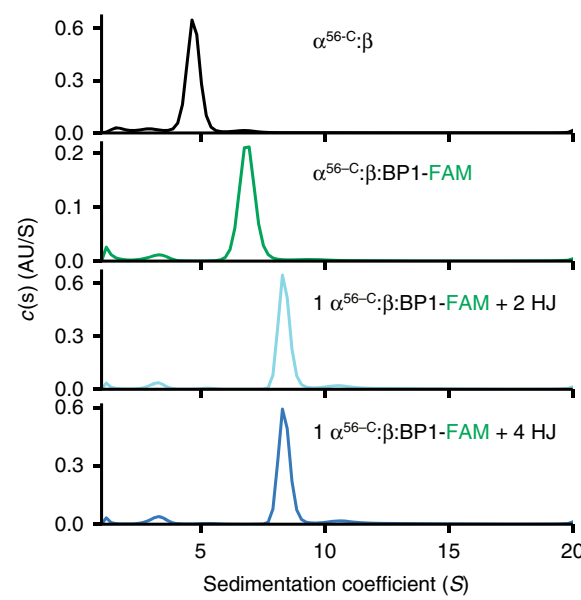

\begin{tabular}{|c|c|c|c|c|c|}
\hline Protein sample & $\begin{array}{c}\text { Friction } \\
\text { ratio }\end{array}$ & $\begin{array}{l}\text { Sed. } \\
\text { coef. } \\
\text { (S) }\end{array}$ & $\begin{array}{c}\text { MWobs. } \\
\text { (kDa) }\end{array}$ & $\begin{array}{l}\text { Predicted } \\
\text { stoichiometry }\end{array}$ & $\begin{array}{c}\text { MWtheo } \\
(\mathrm{kDa})\end{array}$ \\
\hline $\begin{array}{l}16 \mu \mathrm{M} \text { Mis } 18 \alpha^{56-\mathrm{C}} \\
8 \mu \mathrm{M} \text { Mis } 18 \beta\end{array}$ & 1.73 & 4.67 & 125 & $\alpha: \beta=4: 2$ & 130 \\
\hline $\begin{array}{l}7 \mu \mathrm{M} \text { Mis } 18 \alpha^{56-C} \\
\text { 3.5 } \mathrm{M} \text { Mis } 18 \beta \\
\text { 3.5 } \mu \mathrm{M} \text { MBP-M18BP } 1^{1-228} \text {-FAM }\end{array}$ & 1.90 & 6.89 & 260 & $\alpha: \beta: B P 1=4: 2: 2$ & 268 \\
\hline $\begin{array}{l}12 \mu \mathrm{M} \text { Mis } 18 \alpha^{56-C} \\
6 \mu \mathrm{M} \text { Mis18 } \\
6 \mu \mathrm{M} \text { MBP-M18BP } 1^{1-228} \text {-FAM } \\
6 \mu \mathrm{M} \text { MBP-HJURP }{ }^{394-\mathrm{C}}\end{array}$ & 1.90 & 8.39 & 347 & $\alpha: \beta: B P 1: H J=4: 2: 2: 1$ & 350 \\
\hline $\begin{array}{l}12 \mu \mathrm{M} \text { Mis } 18 \alpha^{56-C} \\
6 \mu \mathrm{M} \text { Mis } 18 \beta \\
6 \mu \mathrm{M} \text { MBP-M18BP1 }{ }^{1-228}-\text { FAM } \\
12 \mu \mathrm{M} \text { MBP-HJURP }{ }^{394-C}\end{array}$ & 1.93 & 8.39 & 354 & $\alpha: \beta: B P 1: H J=4: 2: 2: 1$ & 350 \\
\hline
\end{tabular}

impair the stoichiometry of the Mis18 core complex, thus ruling out that impaired HJURP binding was caused by an indirect effect on the stability of the Mis18 complex (Supplementary Fig. 7c).

To validate these results in vivo, we created stable HeLa cell lines and co-expressed EGFP-Mis18aV211D with mCherryHJURP in cells depleted of endogenous Mis18a (Fig. 8d).
EGFP-Mis18a V211D localized to centromeres in the early G1 phase and showed equivalent fluorescence intensity to EGFPMis18aWT. However, EGFP-Mis18a $a^{\mathrm{V} 211 \mathrm{D}}$ did not rescue the localization of mCherry-HJURP when endogenous Mis18a was depleted (Fig. 8e-g). Furthermore, expression of EGFPMis18a $a^{\mathrm{V} 211 \mathrm{D}}$ in presence of endogenous Mis18a had a strong 
Fig. 6 Reconstitution of Mis18-HJURP complex and determination of its molecular stoichiometry. $\mathbf{a}$, b Results of amylose-resin pull-down assays showing that HJURP forms a complex with M18BP1 only in presence of Mis18core. Binding buffer B was used for these pull-down assays. c-e Analytical SEC experiments were performed to confirm that both HJURP and M18BP1 bind Mis18core simultaneously without dissociation of Mis18core. Proteins were mixed in buffer at the following concentrations: Mis18core (hexamer), $5 \mu \mathrm{M}$; MBP-HJURP394-C, $10 \mu \mathrm{M}$; MBP-M18BP1-228, 10 $\mu$ M. SDS-PAGE gels were stained with CBB. $\mathbf{f}$ Sedimentation coefficient distributions obtained from the sedimentation velocity AUC experiments using the protein samples described in the figure. Data profiles used for curve-fitting analyses are shown in Supplementary Fig. 6e. g A table showing the values obtained from the AUC

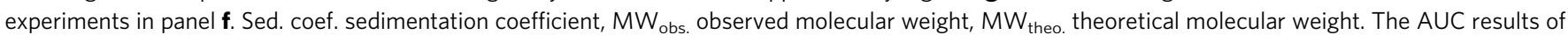
Mis18 $\alpha^{56-C}:$ Mis18 $\beta$ presented here $(\mathbf{f}, \mathbf{g})$ are identical with those presented in Fig. 5g, $\mathbf{h}$

dominant-negative effect on centromere recruitment of mCherryHJURP, likely because it binds endogenous M18BP1 (Fig. 8e-g).

\section{Discussion}

CENP-A is the epigenetic marker of centromeres, and dissecting the molecular basis of its deposition and maintenance through subsequent cell divisions is expected to clarify the foundations of centromere inheritance. A successful molecular model of CENPA deposition ought to include answers to several crucial questions, including: (1) why is the deposition reaction limited to the existing CENP-A domain? (2) Does the deposition reaction target for eviction and replacement a specific neighboring nucleosome, e.g., an H3 nucleosome marked by particular interactions with neighboring CENP-A nucleosome(s)? And (3) what limits the deposition reaction so that the levels of newly deposited CENP-A match the levels of already existing CENP-A, thus ensuring that the amounts of CENP-A are maintained through the generations?

In recent years, initial answers to these questions have emerged. We have learned that CENP-A deposition occurs during the late telophase/early G1 phase of the cell cycle, when Cdk activity is lowest ${ }^{16,17}$. The deposition reaction is complex, and there is growing evidence that it "reads" particular structures at the centromere to force deposition of new CENP-A very near the existing pool ${ }^{10,20,35-41,43-46,48,55-58}$. In a very interesting recent twist, HJURP has also been implicated in the retention of CENP$A$ at centromeres during DNA replication, when CENP-A is equally distributed to the sister chromatids ${ }^{68}$, thus expanding the functional horizon of the deposition machinery.

The study presented here provides answers that are especially relevant to questions 1 and 3. Our characterization of the interaction between the Mis18core and HJURP forces a revision of several previous claims on its molecular mechanism and significance. HJURP and related proteins only bind to a CENP-A:H4 dimer, not a tetramer ${ }^{69-71}$. Thus, a model postulating HJURP dimerization on its centromere-targeting factors is appealing, as it suggests a mechanism for how a CENP-A:H4 tetramer may be reconstituted ${ }^{33}$. Albeit attractive, this model seems incompatible with our new observations. While we could not raise evidence supporting HJURP dimerization, we provide strong evidence that a single molecule of HJURP binds to the Mis 18 complex. Our data are in principle compatible with the possibility that the same Mis18:HJURP complex generates a tetramer in two subsequent steps (with intervening new loading of CENP-A:H4) or that two HJURP:CENP-A:H4 complexes bind to the Mis18 receptor sequentially and deposit two CENP-A:H4 dimers for tetramerization (Fig. 8h, right). Alternatively, and more likely, two closely positioned Mis18:HJURP complexes deposit distinct CENP-A:H4 dimers for tetramerization into the same nucleosome (Fig. $8 \mathrm{~h}, \mathrm{left}$ ), a possibility supported by $2: 1$ stoichiometry of the CCAN:CENP-A nucleosome complex ${ }^{57}$.

In their work, Zasadzinska et al. (2013) ${ }^{33}$ also reported that non-overlapping HJURP constructs containing either R1 or R2 were both capable of reaching kinetochores, and explained this with a direct kinetochore recruitment function of $\mathrm{R} 1$, and a dimerization of $\mathrm{R} 2$ that allows it to dimerize with the endogenous
HJURP. We show here instead that deletion of R1 or R2 from full-length HJURP impairs kinetochore recruitment both in presence and absence of endogenous HJURP, and that constructs containing two copies of R1 or R2 localize to kinetochore after depletion of the endogenous protein. A significant technical difference is that we used stable transgene integration at a single chromosomal site, whereas Zasadinska et al. ${ }^{33}$ operated under condition of transient-transfection of a pIC113 plasmid containing a constitutive CMV promoter, and thus likely under conditions of over-expression.

Another important conclusion of our study is that binding to HJURP ${ }^{394-C}$ does not change the oligomerization state of the Mis $18^{\text {core }}$ complex as previously proposed ${ }^{8}$. Although other regions of HJURP might be responsible for Mis $18^{\text {core }}$ dissociation in living cells, the fact that HJURP ${ }^{1-393}$ does not bind Mis $18^{\text {core }}$ conflicts with this idea. Furthermore, Nardi et al. ${ }^{8}$ observed dissociation of Mis $18^{\text {core }}$ by HJURP in vitro when using a Cterminal segment of HJURP with similar span to the one we have used. While we cannot pinpoint the reasons for these differences, we note that our conclusion that only one HJURP ${ }^{394-C}$ binds to the Mis18 octamer and that the complex does not dissociate were obtained with analytical ultracentrifugation, the gold standard for this purpose.

Genetic code expansion coupled with amber-codon suppression has emerged as a method of choice for the introduction of new functionalities in proteins ${ }^{64}$. Here, we used this powerful methodology with two different photo-activatable cross-linkers, coupled with mass spectrometry, to identify the binding site of HJURP on its centromere receptor. We find that the two HJURP repeats $\mathrm{R} 1$ and $\mathrm{R} 2$ bind on two equivalent 3-helical bundles assembled by the C-terminal regions of two Mis18a and one Mis18 $\beta$ subunits. We also discovered that the $\mathrm{N}$-terminal region of Mis $18 \alpha$ contains a sequence motif whose deletion strongly facilitates the interaction of the Mis $18^{\text {core }}$ complex with HJURP. This motif aligns with the R1 and R2 repeats (Fig. 4g), leading us to speculate that in the absence of HJURP, it folds intramolecularly on the HJURP-binding sites to occlude them and avoid untimely binding. Our future studies will aim to test this speculative idea and to assess its significance for CENP-A deposition.

Collectively, our findings are particularly relevant to question 3 above, namely what ensures that the levels of newly deposited CENP-A match the levels of existing CENP-A. An attractive idea is that there is a licensing step analogous to the one limiting initiation of DNA replication from any given origin to once per cell cycle ${ }^{72}$. Our observations do not discard the idea altogether, but are inconsistent with the identification of Mis18 $8^{\text {core }}$ dissociation as a termination step of the loading reaction ${ }^{8}$. A conceptually alternative mechanism for question 3 is that the deposition reaction is enzymatic and terminates when all the "substrate", such as the CENP-A-H3 di-nucleosome that we have postulated (see Introduction and ref. ${ }^{1}$ ), is processed and turned over into a CENP-A-CENP-A di-nucleosome product, causing the release of the "enzyme". This model postulates that centromere licensing of CENP-A deposition consists in the identification of a particular $\mathrm{H} 3$ nucleosome introduced during DNA 
a<smiles>CC(C)CCCNC(=O)OCCC1(C)N=N1</smiles>

C

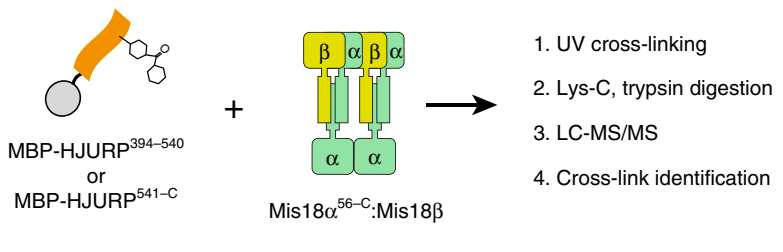

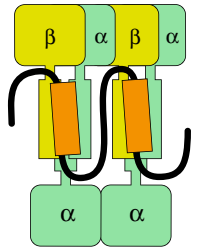

b

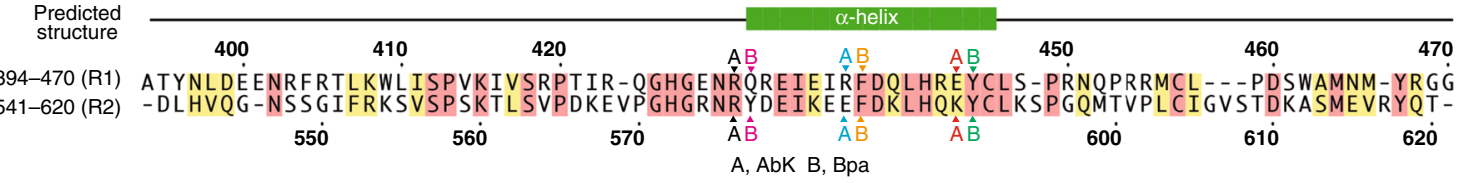

d

\begin{tabular}{|c|c|c|c|c|c|c|c|c|}
\hline \multicolumn{3}{|c|}{ F438Bpa } & \multicolumn{3}{|c|}{ Y445Bpa } & \multicolumn{3}{|c|}{ F584Bpa } \\
\hline Protein & Res. & $\mathrm{N}$ & Protein & Res. & $\mathrm{N}$ & Protein & Res. & $\mathrm{N}$ \\
\hline \multirow{4}{*}{ 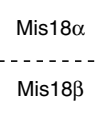 } & S204 & 1 & \multirow{4}{*}{ Mis $18 \alpha$} & A214 & 4 & \multirow{2}{*}{ Mis $18 \alpha$} & E202 & \multirow{2}{*}{$\begin{array}{l}2 \\
1\end{array}$} \\
\hline & Q207 & 1 & & L215 & 1 & & M208 & \\
\hline & $\mathrm{H} 161$ & 1 & & M217 & 4 & \multirow[b]{2}{*}{ Mis18 $\beta$} & S166 & \multirow{2}{*}{$\begin{array}{l}1 \\
4\end{array}$} \\
\hline & S165 & 3 & & $\begin{array}{l}\text { K218 } \\
\text { L } 219\end{array}$ & $\begin{array}{l}4 \\
1\end{array}$ & & M214 & \\
\hline & & & & L205 & 1 & & & \\
\hline & & & Mis $18 \beta$ & $\mathrm{H} 207$ & 3 & & & \\
\hline & & & & K211 & 1 & & & \\
\hline \multicolumn{6}{|c|}{ Y577Bpa } & \multicolumn{3}{|c|}{ Y591Bpa } \\
\hline Protein & Res. & $\mathrm{N}$ & Protein & Res. & $\mathrm{N}$ & Protein & Res. & $\mathrm{N}$ \\
\hline \multirow{13}{*}{ Mis $18 \alpha$} & T155 & 1 & \multirow{13}{*}{ Mis18 $\beta$} & L5 & 1 & \multirow{6}{*}{ Mis $18 \alpha$} & A214 & 10 \\
\hline & P156 & 1 & & R9 & 1 & & L215 & 14 \\
\hline & Q184 & 3 & & S10 & 2 & & M217 & 5 \\
\hline & |185 & 8 & & A13 & 1 & & K218 & 10 \\
\hline & V186 & 1 & & T14 & 1 & & L219 & 2 \\
\hline & S187 & 6 & & P16 & 1 & & E223 & 4 \\
\hline & D101 & o & & C171 & 1 & \multirow{7}{*}{ Mis18 $\beta$} & 510 & 2 \\
\hline & E191 & y & & P191 & 17 & & A103 & 2 \\
\hline & L192 & 8 & & L192 & 6 & & Y172 & 1 \\
\hline & F193 & 7 & & S193 & 20 & & L210 & 1 \\
\hline & S197 & 1 & & E194 & 3 & & K211 & 1 \\
\hline & S204 & 1 & & K195 & 5 & & L213 & 1 \\
\hline & F228 & 1 & & I196 & 2 & & M214 & 6 \\
\hline
\end{tabular}
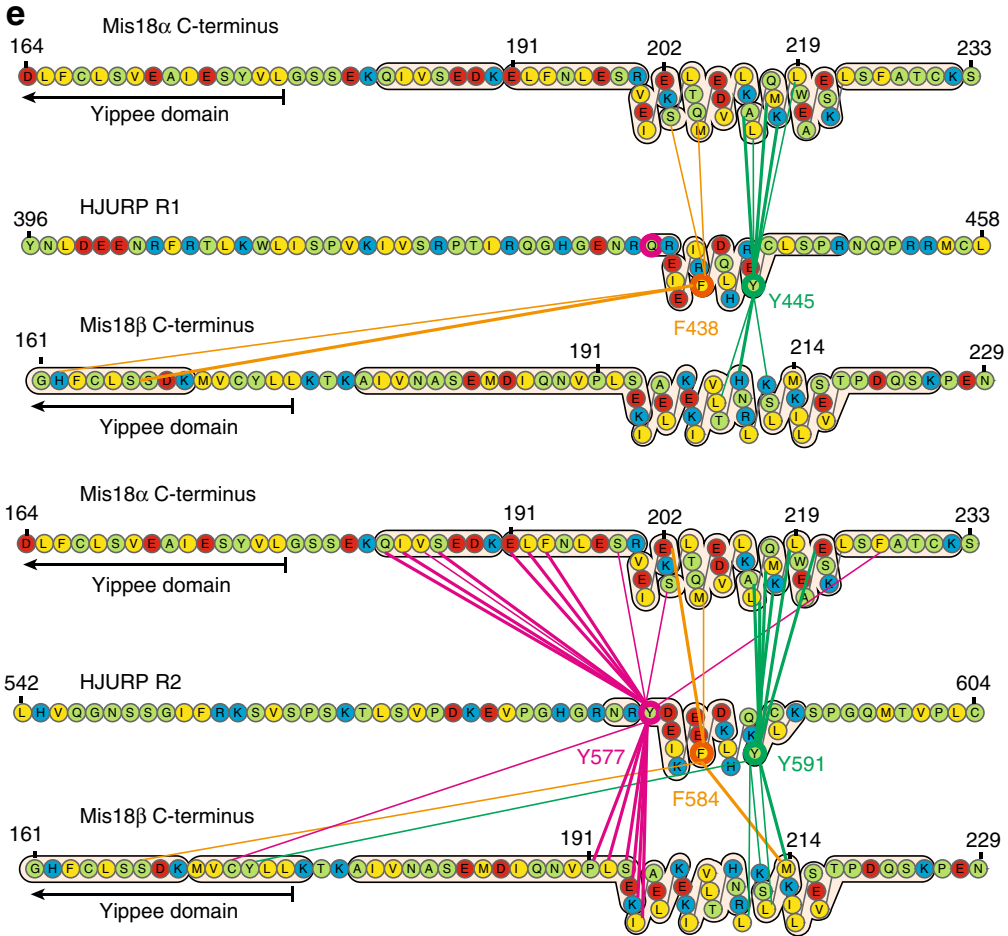

f

\begin{tabular}{|c|c|c|c|c|c|}
\hline \multicolumn{3}{|c|}{ E444AbK } & \multicolumn{3}{|c|}{ K590AbK } \\
\hline Protein & Res. & $\mathrm{N}$ & Protein & Res. & $\mathrm{N}$ \\
\hline \multirow[t]{2}{*}{ Mis18 $\alpha$} & K218 & 3 & & K218 & 3 \\
\hline & L210 & 4 & Mis $18 \alpha$ & $\begin{array}{l}\text { L219 } \\
\text { E221 }\end{array}$ & $\begin{array}{l}2 \\
4\end{array}$ \\
\hline \multirow[t]{3}{*}{ Mis18 $\beta$} & L213 & 3 & & E221 & 4 \\
\hline & K215 & 1 & \multirow{2}{*}{ Mis18 $\beta$} & K211 & 2 \\
\hline & & & & $\mathrm{L} 213$ & 3 \\
\hline \multicolumn{3}{|c|}{ E583AbK } & & & \\
\hline Protein & Res. & $\mathrm{N}$ & & & \\
\hline \multirow{2}{*}{ Mis $18 \alpha$} & Y161 & 1 & & & \\
\hline & E188 & 1 & & & \\
\hline
\end{tabular}

g Bpa-cross-linked residues

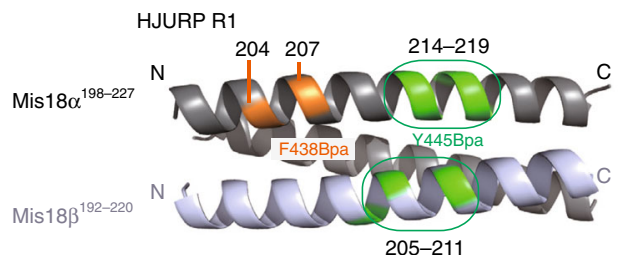

HJURP R2

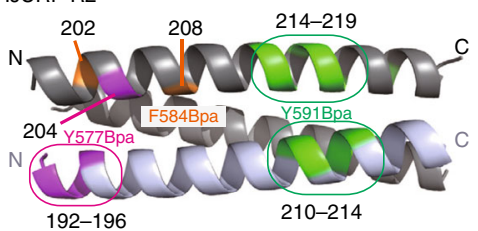

AbK-cross-linked residues

HJURP R1

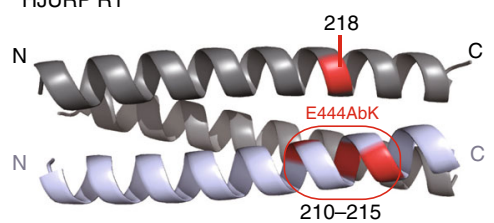

HJURP R2

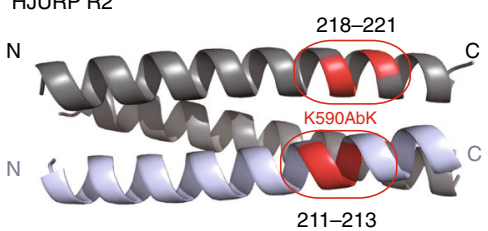

replication and residing in the vicinity of CENP-A, i.e., in the generation of a suitable substrate. We speculate that generation of the substrate entails that this $\mathrm{H} 3$ nucleosome readily binds CCAN subunits, including CENP-C and possibly CENP-T, that later attract the deposition machinery. A formal analysis of this model will require the identification of the exact determinants of Mis 18 complex recruitment and activation at centromere, i.e., of the exact substrate of the deposition reaction.

\section{Methods}

Plasmids. Codon-optimized cDNAs of human Mis18a, Mis18 $\beta$, M18BP1, and HJURP were purchased from GeneArt. Subcloning and plasmid construction were 
Fig. 7 UV-cross-linking and MS analysis reveal equivalent binding sites of HJURP R1 and R2 on Mis18 C-terminal helix-bundle. a Chemical structures of $p$ benzoyl-L-phenylalanine (Bpa) and 3'-azibutyl-N-carbamoyl-lysine (AbK). b Amino-acid sequences of HJURP showing positions where Bpa or AbK were introduced by amber-codon suppression. Bpa was introduced into position 431, 438, 445, 577, 584, or 591. AbK was introduced into position 430, 437, $444,576,583$, or 590. c Schematic description of the UV-cross-linking experiment followed by MS analysis. d Cross-links identified by MS analysis of Bpacross-linked samples. Res. residue, $\mathrm{N}$ numbers of identification. e Schematic representation of cross-links identified between the incorporated Bpa residues in HJURP R1 or R2 and the residues in C-terminal regions of Mis18 $\alpha$ and Mis18 $\beta$. $\mathbf{f}$ Cross-links identified by MS analysis of AbK-cross-linked samples. $\mathbf{g}$ Bpaand AbK-cross-linked residues are highlighted in colors on a 3D model of three-helix-bundle of Mis18 $\alpha$ and Mis18 $\beta$. The details of cross-links identified can be found in Supplementary Data 2

performed using standard restriction-enzyme-based cloning, Gibson cloning ${ }^{73}$, and PCR-based site-directed mutagenesis methods. The coding DNA sequences (CDS) of genes of interest in all expression plasmids were verified by DNA sequencing before using for further experiments. A list of plasmids used in this study can be found in Supplementary Data 1.

Escherichia coli (E. coli) expression plasmids pETDuet-MBP-HJURP-8His variants and pETDuet-MBP-M18BP1-8His variants were generated by inserting PCR-amplified CDSs of HJURP and M18BP1 into pETDuet-MBP-8His vector ${ }^{52}$ between the N-terminal MBP-tag and the C-terminal 8His-tag using BamHI and XhoI sites. E. coli expression plasmids pETDuet-6His-Mis18a-MBP-Mis18 $\beta$ variants were generated from pETDuet-6His-Mis18 $\alpha$-MBP-Mis $18 \beta^{52}$ by replacing the CDSs of full-length Mis 18 and/or full-length Mis $18 \beta$ with the CDSs of different shorter fragments. Point mutations were introduced by PCR-based site-directed mutagenesis.

Mammalian expression plasmid pcDNA5-EGFP-NLS-IRESv12-SNAP-CENP-A was generated from a modified pcDNA5/FRT/TO plasmid (Thermo Fisher Scientific), pcDNA5/FRT/TO-EGFP-IRES ${ }^{74}$. A CDS of nuclear localization signal (NLS) from simian virus 40 was placed between the CDSs of EGFP and IRES, and the CDSs of SNAP-tag and human CENP-A were subcloned from pETDuetCENP-A-SNAP-HA-PGK-NeoR ${ }^{52}$ using Gibson cloning. Mutations were introduced into IRES according to a previous study ${ }^{75}$ to obtain the IRESv12 with reduced translation efficiency. Plasmid pcDNA5-EGFP-NLS-IRESv12-SNAPCENP-A enables co-expression of EGFP-NLS under the regulation of $\mathrm{CMV} / \mathrm{TetO}_{2}$ promoter and SNAP-CENP-A under the control of IRESv12 with much reduced expression level. The plasmid pcDNA5-EGFP-HJURP-IRESv12-SNAP-CENPA for co-expression of EGFP-HJURP and SNAP-CENP-A was generated by replacing the CDS of NLS of pcDNA5-EGFP-NLS-IRESv12-SNAP-CENP-A with human HJURP original CDS from genomic DNA (the internal BamHI site was removed) using BamHI and XhoI sites. The plasmids for co-expression of EGFP-HJURP variants with SNAP-CENP-A were generated by PCR-based site-directed mutagenesis or restriction-site-based ligation. Especially, pcDNA5-EGFP-HJURP (R1-R1)-IRESv12-SNAP-CENPA was generated by replacing the CDS of NLS of pcDNA5-EGFP-NLS-IRESv12-SNAP-CENP-A with a ligation product of three HJURP DNA fragments that encode HJURP ${ }^{1-532}$, HJURP ${ }^{394-532}$, and HJURP ${ }^{672-748}$. And pcDNA5-EGFP-HJURP(R2-R2)-IRESv12-SNAP-CENPA was generated by replacing the CDS of NLS of pCDNA5-EGFP-NLS-IRESv12-SNAPCENP-A with a ligation product of three HJURP DNA fragments that encode HJURP ${ }^{1-393}$, HJURP ${ }^{533-671}$, and HJURP ${ }^{533-748}$. Plasmids pcDNA5-EGFPMis18a-IRESv12-SNAP-CENPA and pcDNA5-EGFP-Mis18a(56-C)-IRESv12SNAP-CENPA were generated by replacing the CDS of NLS of pcDNA5-EGFPNLS-IRESv12-SNAP-CENP-A with the codon-optimized CDSs of Mis18a or Mis18a $a^{56-233}$. Plasmid pcDNA5-EGFP-Mis18a-P2AT2A-mCherry-HJURPIRESv12-SNAP-CENP-A for co-expression of EGFP-Mis18a, mCherry-HJURP, and SNAP-CENP-A was constructed by inserting the CDSs of Mis18a, P2AT2A ${ }^{52}$ and mCherry-tag between the CDSs of EGFP and HJURP of pcDNA5-EGFPHJURP-IRESv12-SNAP-CENPA using Gibson cloning. A point mutation of Mis18a V211D was introduced into this plasmid by PCR-based site-directed mutagenesis to obtain pcDNA5-EGFP-Mis18(V211D)-P2AT2A-mCherry-HJURPIRESv12-SNAP-CENPA.

Plasmid pEVOL-ABK (Addgene \#126035) was generated by replacing the CDSs of the amber suppressor tRNA/aminoacyl-tRNA synthetase pairs for Bpa $\left(\text { tRNA }^{\text {Tyr}} / \text { Bpa-RS) of pEVOL-pBpF (Addgene } \# 31190\right)^{76}$ with the CDSs of the amber suppressor tRNA/aminoacyl-tRNA synthetase pairs for AbK (tRNA ${ }^{\mathrm{Pyl}} /$ AbK-RS). The CDSs of AbK-RS was subcloned from pDULE-ABK (Addgene $\# 49086)^{59}$ into two positions in pEVOL plasmid. One CDS of AbK-RS was placed between $a r a B A D$ promoter and $r r n B$ terminator, and the other CDS of AbK-RS was placed between $g l n S$ ' promoter and $g \ln S \mathrm{~T}$ terminator according to the original design of $\mathrm{pEVOL}$ plasmid. The CDS of tRNA ${ }^{\mathrm{Pyl}}$ is placed between proK promoter and proK terminator. A previously reported mutation (U25G) ${ }^{77}$ was introduced to the sequence of tRNA ${ }^{\mathrm{Py}}$ to improve the efficiency of amber suppression.

Chemical synthesis of $\mathbf{3}^{\prime}$-azibutyl-N-carbamoyl-lysine. Unnatural amino-acid $3^{\prime}$-azibutyl- $N$-carbamoyl-lysine (AbK) 1 (Fig. 7a, Supplementary Fig. 8) was synthesized following the scheme published previously ${ }^{78}$.

First, we synthesized diazirine 2 (Supplementary Fig. 8) from 4-hydroxy-2butanone. Under slow stirring, 4-hydroxy-2-butanone ( $20 \mathrm{~g}, 0.22 \mathrm{~mol}$ ) was added to liquid $\mathrm{NH}_{3}(120 \mathrm{~mL})$ at $-78^{\circ} \mathrm{C}$, followed by another $5 \mathrm{~h}$ stirring at $-78^{\circ} \mathrm{C}$.
Subsequently, hydroxylamine O-sulfonic acid $(28.2 \mathrm{~g}, 0.24 \mathrm{~mol})$ in methanol $(200 \mathrm{~mL})$ was added, the reaction mixture was allowed to warm up to the ambient temperature and stirred overnight. The white precipitated was removed by filtration and the volume of the filtrate was reduced to $200 \mathrm{~mL}$. The remaining mixture was cooled to $0{ }^{\circ} \mathrm{C}$, followed by the addition of methanol $(200 \mathrm{~mL})$ and freshly distilled triethylamine $(30 \mathrm{~mL})$. Subsequently, iodine $(\sim 28 \mathrm{~g})$ was added until a persistent iodine coloring remained. The reaction mixture was warmed up to the ambient temperature and stirred for another $2 \mathrm{~h}$. Under reduced pressure the volume of the reaction mixture was reduced to $200 \mathrm{~mL}$. The reaction mixture was diluted with brine $(200 \mathrm{~mL})$ and extracted three times with ether $(100 \mathrm{~mL})$. Subsequently, the combined organic phases were dried over anhydrous $\mathrm{MgSO}_{4}$ and the solvent was removed under reduced pressure. Finally, the desired product 2 was obtained in $32 \%$ yield $(7.2 \mathrm{~g})$ as brown oil.

Next, we activate the diazirine $\mathbf{2}$ with disuccinimide carbonate. Under argon atmosphere, $N, N^{\prime}$-disuccinimidyl carbonate $(6 \mathrm{~g}, 23.42 \mathrm{mmol})$ and freshly distilled triethylamine $(8 \mathrm{~mL})$ were added to a mixture of the diazirine $2(1.5 \mathrm{~g}, 14.98 \mathrm{mmol})$ in dry acetonitrile $(40 \mathrm{~mL})$. The reaction mixture was stirred for $20 \mathrm{~h}$ at the ambient temperature and subsequently dried under reduced pressure. The crude product was purified by column chromatography on silica gel using a mixture of acetone and chloroform (20:1). The desired product 3 (Supplementary Fig. 8) was obtained in $97 \%$ yield as an orange solid. $1 \mathrm{H} \mathrm{NMR}\left(400 \mathrm{MHz}, \mathrm{CDCl}_{3}\right) \delta=4.28(\mathrm{t}$, $\mathrm{J}=6.5 \mathrm{~Hz}, 2 \mathrm{H}), 2.75(\mathrm{~s}, 4 \mathrm{H}), 1.77(\mathrm{t}, \mathrm{J}=6.5 \mathrm{~Hz}, 2 \mathrm{H}), 1.10(\mathrm{~s}, 3 \mathrm{H})$.

Under argon atmosphere, Boc-Lys-OH $(4.5 \mathrm{~g}, 18.28 \mathrm{mmol})$ was added to a solution of NHS-carbonate $(3 \mathrm{~g}, 12.44 \mathrm{mmol})$ in dry DMF $(50 \mathrm{~mL})$. The reaction mixture was stirred for $35 \mathrm{~h}$ at room temperature, poured into water $(250 \mathrm{~mL})$ and stirred for another $20 \mathrm{~min}$. Following an extraction with ether $(3 \times 75 \mathrm{~mL})$, the combined organic phases were washed with brine $(2 \times 75 \mathrm{~mL})$ and dried over anhydrous $\mathrm{MgSO}_{4}$. Subsequently, the solvent was removed under reduced pressure and the desired product $\mathbf{4}$ (Supplementary Fig. 8) was obtained in $79 \%$ yield as orange oil. ${ }^{1} \mathrm{H}$ NMR $(400 \mathrm{MHz}$, Chloroform- $d) \delta 6.14(\mathrm{~s}, 0.5 \mathrm{H}), 5.24(\mathrm{~s}, 1 \mathrm{H}), 4.94$ $(\mathrm{s}, 0.5 \mathrm{H}), 4.29(\mathrm{~s}, 1 \mathrm{H}), 4.12-3.94(\mathrm{~m}, 2 \mathrm{H}), 3.26-3.13(\mathrm{~m}, 2 \mathrm{H}), 1.92-1.33(\mathrm{~m}, 17 \mathrm{H})$, $1.05(\mathrm{~s}, 3 \mathrm{H})$.

Finally, the Boc group was removed from 4 . The Boc-amine $4(1.5 \mathrm{~g}, 4.03 \mathrm{mmol})$ and triethylsilane $(1.28 \mathrm{~mL})$ were dissolved at the ambient temperature by slow addition of $5 \%$ TFA in dichloroethane $(65 \mathrm{~mL})$. The reaction mixture was stirred for $18 \mathrm{~h}$ and the volatile components were removed under reduced pressure. The remaining residue was dissolved in methanol $(24 \mathrm{~mL})$ and precipitated by drop-wise addition into ether $(200 \mathrm{~mL})$ under vigorous stirring. The precipitation process was repeated once more and provided the desired product $\mathbf{1}(0.79 \mathrm{~g})$ as a white crystalline solid in $72 \%$ yield. $1 \mathrm{H}$ NMR $\left(500 \mathrm{MHz}, \mathrm{D}_{2} \mathrm{O}\right) \delta 3.84(\mathrm{t}, \mathrm{J}=6.0 \mathrm{~Hz}, 2 \mathrm{H}), 3.62(\mathrm{t}, \mathrm{J}=$ $9.1 \mathrm{~Hz}, 1 \mathrm{H}), 2.97(\mathrm{t}, 2 \mathrm{H}), 1.81-1.65(\mathrm{~m}, 2 \mathrm{H}), 1.57-1.44(\mathrm{~m}, 2 \mathrm{H}), 1.39-1.34(\mathrm{~m}, 2 \mathrm{H})$, $1.28-1.19(\mathrm{~m}, 2 \mathrm{H}), 0.86(\mathrm{~s}, 3 \mathrm{H}) .{ }^{13} \mathrm{C} \mathrm{NMR}\left(126 \mathrm{MHz}, \mathrm{D}_{2} \mathrm{O}\right) \delta 174.04,158.38,60.40$, $54.09,39.77,33.13,29.78,28.39,24.89,21.43,18.58$. LRMS: calc. $[\mathrm{M}+\mathrm{H}]^{+}$273.31, found 273.04

Protein expression and purification. Insect-cell-expressed Mis18a:Mis18 $\beta$ complex used in the pull-down assays was expressed and purified using the method reported previously ${ }^{52}$. Other proteins used in this study, except Bpa-incorporated and AbK-incorporated MBP-HJURP variants, were expressed in E. coli cells of BL21-CodonPlus(DE3)-RIL strain (Agilent Technologies, \#230240) and purified using the method reported previously ${ }^{52}$ with minor modification. E. coli cells transformed with expression plasmids were cultured in $2 \times \mathrm{YT}$ media $\left(16 \mathrm{~g} \mathrm{~L}^{-1}\right.$ tryptone, $10 \mathrm{~g} \mathrm{~L}^{-1}$ yeast extract, $5 \mathrm{~g} \mathrm{~L}^{-1} \mathrm{NaCl}$ ) supplemented with ampicillin and chloramphenicol at $37^{\circ} \mathrm{C}$. Protein expression was induced by adding IPTG to the final concentration of $0.2 \mathrm{mM}$ when $\mathrm{OD}_{600}$ of the culture reached 0.6 and further incubation at $20^{\circ} \mathrm{C}$ for $16 \mathrm{~h}$. Then E. coli cells expressing proteins of interest were suspended in buffer HST300 (30 mM HEPES pH 7.5, $300 \mathrm{mM}$ sodium chloride, $1 \mathrm{mM}$ TCEP) containing $1 \mathrm{mM}$ PMSF and $10 \mathrm{mM}$ imidazole and lysed by sonication. The clear supernatant obtained after centrifugation was incubated with $\mathrm{Ni}$ resin (Roche) for $\sim 16 \mathrm{~h}$. Protein-bound resin was washed with 100 column volumes of buffer HST300 containing $10 \mathrm{mM}$ imidazole. Proteins were eluted with buffer HST300 containing $400 \mathrm{mM}$ imidazole and concentrated in buffer HST300. The concentration of imidazole was reduced to less than $40 \mathrm{mM}$ by repetitive dilution of the concentrated protein sample with buffer HST300. MBP-HJURP variants were further purified using a Superdex 200 10/300 GL SEC column (GE Healthcare) with buffer HST300. After the Ni-affinity purification, the variants of $E$. coli expressed Mis18a:Mis18 $\beta$ complex were incubated with TEV protease for $\sim 16 \mathrm{~h}$ at 
Mutated residues

Mis $18 \alpha^{198-227}$

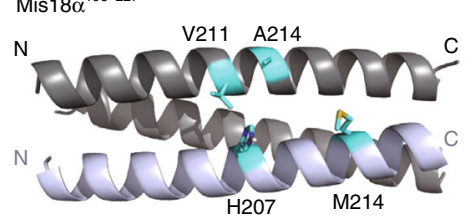

Mis $18 \beta^{192-220}$

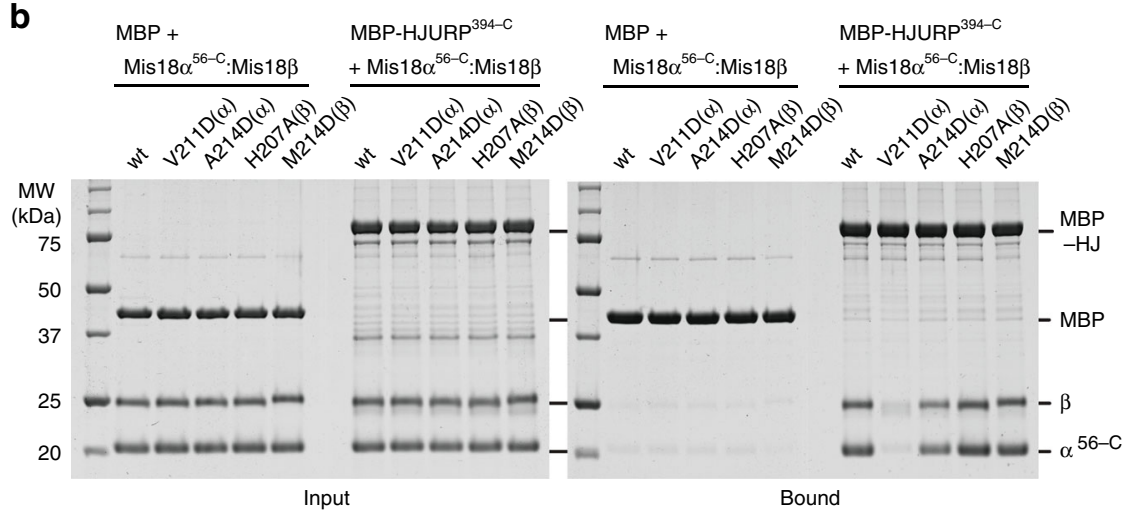

e
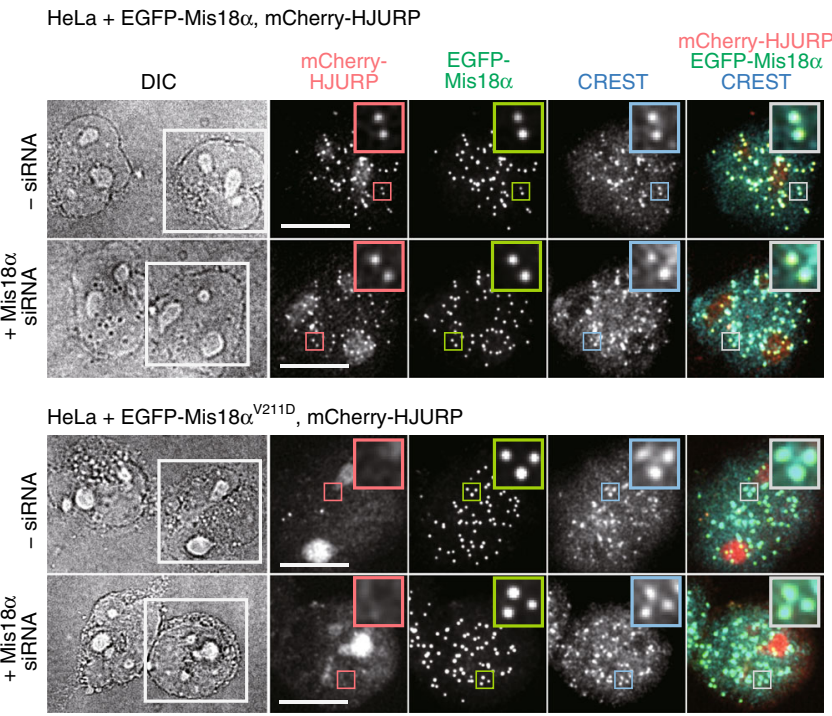

h

Coordinated deposition by two HJURP

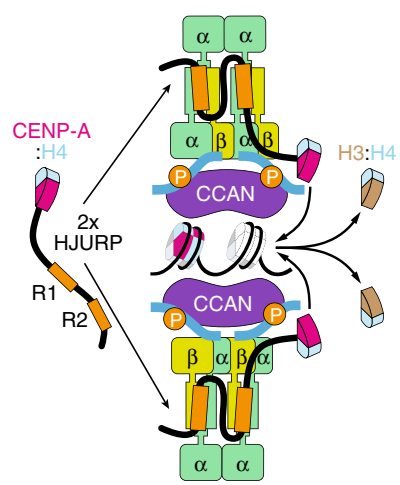

Sequential deposition

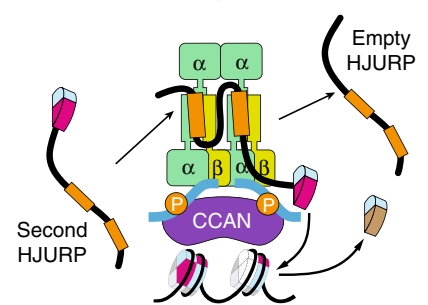

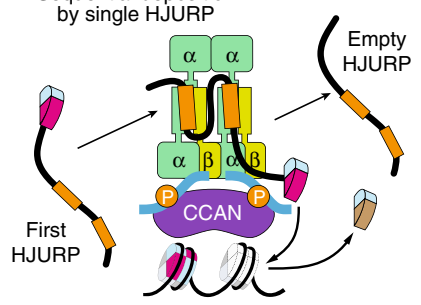

Fig. $8 \mathrm{Mis} 18^{\mathrm{V} 211 \mathrm{D}}$ is a separation-of-function mutant with impaired HJURP binding but not M18BP1 binding. a Mutated residues of Mis18 $\alpha$ and Mis18 $\beta$ are indicated on the 3D model. $\mathbf{b}, \mathbf{c}$ SDS-PAGE results of the amylose-resin pull-down assays for testing the interaction of the mutants of Mis18 $\alpha$ and Mis18 $\beta$ with HJURP394-C, M18BP1-60, and M18BP161-140. d Western blotting analysis confirming transgene expression. Endo. endogenous. e Representative images showing the fluorescence of mCherry-HJURP and EGFP-Mis18 $\alpha$ variants in fixed HeLa cells treated as described in Fig. 2a but without the blocking and labeling steps of SNAP-CENP-A. Mis18 $\alpha$ siRNA was used instead of HJURP siRNA. White scale bars indicate $10 \mu \mathrm{m}$. $\mathbf{f}, \mathbf{g}$ Quantification of the centromere fluorescence intensity of mCherry-HJURP and EGFP-Mis18 $\alpha$ variants. The bar graphs represent mean values from three replicate experiments (blue dots indicate the mean values from each experiment). Error bars indicate standard deviations. h Two models of HJURP recruitment to the Mis18 receptor and the deposition of CENP-A:H4 dimers. Source data are provided as a Source Data file 
$4{ }^{\circ} \mathrm{C}$ for cleavage of the 6 His-tag and MBP-tag and were purified using the Superdex 200 10/300 GL SEC column with buffer HST300.

The Bpa-incorporated or AbK-incorporated MBP-HJURP variants were expressed in E. coli cells of BL21(DE3) strain (Agilent Technologies, \#200131). Plasmids carrying MBP-HJURP genes with TAG codon at the specific positions were used for transformation of the E. coli cells together with pEVOL-pBpF or pEVOL-ABK. The cells were cultured in $2 \times$ YT media supplemented with ampicillin, chloramphenicol and $0.2 \%$ arabinose at $37^{\circ} \mathrm{C}$. Protein expression was induced by adding IPTG to the final concentration of $0.2 \mathrm{mM}$ and the unnatural amino-acids (Bpa or $\mathrm{AbK}$ ) to the final concentration of $1 \mathrm{mM}$ when $\mathrm{OD}_{600}$ of the culture reached 0.6. The culture was further incubated at $25^{\circ} \mathrm{C}$ for $16 \mathrm{~h}$. Purification of the Bpa-incorporated and AbK-incorporated MBP-HJURP variants was performed in the same way as normal MBP-HJURP variants described above.

Amylose-resin pull-down assay. Proteins were diluted to $5 \mu \mathrm{M}$ in $40 \mu \mathrm{L}$ binding buffer A (30 mM HEPES pH 7.5, $300 \mathrm{mM}$ sodium chloride, $1 \mathrm{mM}$ TCEP, $0.01 \%$ Tween-20) or binding buffer B (15 mM HEPES pH 7.5, $150 \mathrm{mM}$ sodium chloride, $1 \mathrm{mM}$ TCEP, $0.01 \%$ Tween-20), and mixed with $20 \mu \mathrm{L}$ amylose resin (NEB) equilibrated with the binding buffer. One-third of this mixture was taken as input fraction and the rest two-thirds were incubated at $4{ }^{\circ} \mathrm{C}$ for $30 \mathrm{~min}$. Amylose-bound proteins were separated from unbound fraction by spinning down the amylose resin and washing the resin with $500 \mu \mathrm{L}$ binding buffer four times. The input and bound fractions were analyzed by Tricine-SDS-PAGE. The gels were stained with Coomassie brilliant blue (CBB).

Analytical size-exclusion chromatography (SEC). SEC experiments were performed on a calibrated Superose 6 increase 5/150 GL column (GE Healthcare). Purified protein samples were mixed at $10 \mu \mathrm{M}$ (except Mis18 $\alpha$ at $20 \mu \mathrm{M}$ ) and analyzed under isocratic condition at $4{ }^{\circ} \mathrm{C}$ in buffer containing $15 \mathrm{mM}$ HEPES $\mathrm{pH}$ 7.5, $150 \mathrm{mM}$ sodium chloride and $0.5 \mathrm{mM}$ TCEP at a flow rate of $0.1 \mathrm{~mL} \mathrm{~min}^{-1}$ Fractions were collected and analyzed by Tricine-SDS-PAGE and the gels were stained with $\mathrm{CBB}$.

Protein fluorescence labeling using sortase. MBP-M18BP1 $1^{1-228}$-LPETGG was labeled with GGGGK peptides with a C-terminally conjugated fluorescein amidite (FAM) (Genscript) using purified Sortase $5 \mathrm{M}$ mutant ${ }^{79}$. Labeling was performed for $\sim 16 \mathrm{~h}$ at $4{ }^{\circ} \mathrm{C}$ by incubation of $100 \mu \mathrm{M}$ MBP-M18BP1 $1^{1-228}$-LPETGG with $1 \mathrm{mM}$ GGGGK-FAM peptides and $10 \mu \mathrm{M}$ Sortase $5 \mathrm{M}$ in the reaction buffer containing $50 \mathrm{mM}$ HEPES pH 7.5, $500 \mathrm{mM} \mathrm{NaCl}, 1 \mathrm{mM}$ TCEP and $10 \mathrm{mM} \mathrm{CaCl}_{2}$. His-tagged Sortase was removed by incubation of the reaction mix with $\mathrm{Ni}$ resin (Roche). Excess of GGGGK-FAM peptides were removed by gel filtration.

Analytical ultracentrifugation (AUC). Sedimentation velocity AUC was performed at $42,000 \mathrm{rpm}$ at $20^{\circ} \mathrm{C}$ in a Beckman XL-A ultracentrifuge. Purified protein samples were diluted in buffer HST300 and loaded into standard double-sector centerpieces. The cells were scanned at $280 \mathrm{~nm}$ for unlabeled samples or $488 \mathrm{~nm}$ for FAM-labeled samples. More than 300 scans were recorded for each sample. Data were analyzed using the program SEDFIT ${ }^{80}$ with the model of continuous $c(s)$ distribution. The partial specific volumes of the proteins, buffer density, and buffer viscosity were estimated using the program SEDNTERP. Figures were generated using the program GUSSI.

UV-cross-linking and cross-link identification. The Bpa-incorporated or AbKincorporated MBP-HJURP variants were diluted in $200 \mu \mathrm{L}$ buffer HST300 at $3 \mu \mathrm{M}$ and were incubated with Mis18a ${ }^{56-C}:$ Mis $18 \beta 1.5 \mu \mathrm{M}$ (calculated as hexamer). LED UV light of $365 \mathrm{~nm}$ (Nichia, NCSU276A) was used to irradiate the protein samples for $30 \mathrm{~min}$ on ice to activate the cross-linking reaction. The protein solutions were incubated with $10 \mu \mathrm{L}$ Ni resin (Roche), and MBP-HJURP variants carrying 8Histags at the C-termini bound on Ni resin together with Mis $18 \alpha^{56-C}:$ Mis18 $\beta$. Unbound Mis18 $\alpha^{56-\mathrm{C}}$ :Mis $18 \beta$ was removed by washing the resin with $500 \mu \mathrm{L}$ buffer HST300 for three times. Uncross-linked Mis $18 a^{56-C}$ and Mis18 $\beta$ were removed by washing the resin twice with $100 \mu \mathrm{L} 8 \mathrm{M}$ urea containing $10 \mathrm{mM}$ HEPES $\mathrm{pH} 7.5$ and $1 \mathrm{mM}$ TCEP. Samples were collected at each step and analyzed using Tricine-SDS-PAGE. Cross-linked protein samples on Ni resin were incubated with $8 \mathrm{M}$ urea containing $1 \mathrm{mM}$ DTT at $25^{\circ} \mathrm{C}$ for $30 \mathrm{~min}$. Chloroacetamide was added to the solution to the final concentration of $5.5 \mathrm{mM}$ for alkylation. LysC and trypsin were used to digest the samples at $25^{\circ} \mathrm{C}$ for $\sim 16 \mathrm{~h}$, and the digestion was stopped by adding trifluoroacetic acid (TFA) to the final concentration of $0.2 \%$. Peptides were purified using Sep-Pak tC18 cartridges $(50 \mathrm{mg}$, Waters), eluted in water containing $60 \%$ acetonitrile and $0.1 \%$ TFA, and dried in tubes completely.

LC-MS/MS analysis was performed as previously reported ${ }^{81}$ using an Ultimate 3000 RSLC nano system and a Q-Exactive Plus mass spectrometer (Thermo Fisher Scientific). Peptides were dissolved in water containing $0.1 \%$ TFA and were separated on the Ultimate 3000 RSLC nano system (precolumn: C18, Acclaim PepMap, $300 \mu \mathrm{m} \times 5 \mathrm{~mm}, 5 \mu \mathrm{m}, 100 \AA$, separation column: C18, Acclaim PepMap, $75 \mu \mathrm{m} \times 500 \mathrm{~mm}, 2 \mu \mathrm{m}, 100 \AA$, Thermo Fisher Scientific). After loading the sample on the precolumn, a multistep gradient from $5-40 \%$ B ( $90 \mathrm{~min}), 40-60 \%$ B (5 min),

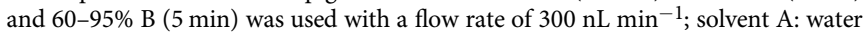
$+0.1 \%$ formic acid; solvent $\mathrm{B}$ : acetonitrile $+0.1 \%$ formic acid. Data were acquired using the Q-Exactive Plus mass spectrometer in data-dependent MS/MS mode. For full scan MS, we used mass range of $\mathrm{m} / z 300-1800$, resolution of $\mathrm{R}=140000$ at $\mathrm{m} / \mathrm{z}$ 200 , one microscan using an automated gain control (AGC) target of $3 \mathrm{e} 6$ and a maximum injection time (IT) of $50 \mathrm{~ms}$. Then, we acquired up to $10 \mathrm{HCD}$ MS/MS scans of the most intense at least doubly charged ions (resolution 17500, AGC target 1e5, IT $100 \mathrm{~ms}$, isolation window $4.0 \mathrm{~m} / \mathrm{z}$, normalized collision energy 25.0 , intensity threshold 2e4, dynamic exclusion $20.0 \mathrm{~s}$ ). All spectra were recorded in profile mode.

Raw data from the Q-Exactive Plus mass spectrometer were converted to Mascot generic files (MGF) format with program msConvert GUI from ProteoWizard Toolkit version $3^{82}$. Program StavroX version 3.6.6. $6^{83}$ was used for cross-link identification. MS data in MGF format and the protein sequences in FASTA format were loaded on the program and the MS spectra matching cross-linked peptides were searched. In the settings of StavroX, the precursor precision and the fragment ion precision were changed to 10.0 and $20.0 \mathrm{ppm}$, respectively, from the default values. For the analysis of $\mathrm{AbK}$-cross-linked samples, a new entry of $\mathrm{AbK}$ with the chemical composition of $\mathrm{C}_{11} \mathrm{H}_{18} \mathrm{~N}_{4} \mathrm{O}_{2}$ was added to the settings section of aminoacids in StavroX. And a new entry of AbK was appended to the cross-linker settings section with the following information: name, $\mathrm{ABK}$; composition, $-\mathrm{N}_{2}$; maximum distance, $30 \AA$; site 1, $z$; site2, \{ABCDEFGHIKLMPQRSTVWY\}, where ' $\{$ ' and ' $\}$ ' are the $\mathrm{N}$ - and $\mathrm{C}$-termini, respectively, and the letters indicate single amino-acids, with $\mathrm{B}$ being alkylated Cys and $\mathrm{z}$ being AbK. StavroX estimates the false discovery rate (FDR) by comparison of the distribution of the cross-link candidates found using provided protein sequences and the distribution of the candidates found from decoy search using shuffled sequences, and 5\% FDR was used as the cutoff to exclude the candidates with lower StavroX scores. The results of cross-link data were exported in comma-separated values (CSV) format. The cross-link candidates with mass deviation outside the range of $10 \mathrm{ppm}$ (Bpa dataset, -3 to $7 \mathrm{ppm}$; AbK dataset, -4 to $6 \mathrm{ppm}$ ) were excluded (Supplementary Data 2). The cross-link maps of the intermolecular cross-links among HJURP, Mis18 $\alpha$ and Mis18 $\beta$ were drawn using Adobe Illustrator software.

Generation of stable HeLa cell lines. All HeLa cell lines used in this study (Supplementary Data 1) were generated from a Flp-In T-REx HeLa cell line created by Stephen Taylor and colleagues ${ }^{61}$. The Flp-In T-REx HeLa cells were transfected with the pcDNA5/FRT/TO derived plasmids and the pOG44 plasmid (Thermo Fisher Scientific) according to the manufacture's protocol. Stable cell lines were generated by isolation of single colonies, which were viable in the DMEM medium containing $10 \%$ tetracycline-free FBS, $2 \mathrm{mM}$ l-glutamine, $250 \mu \mathrm{g} \mathrm{mL}^{-1}$ hygromycin and $4 \mu \mathrm{g} \mathrm{mL}^{-1}$ blasticidin. Protein expression was verified using western blotting (uncropped blot images are included in a Source Data file) and the following antibodies were used: anti-HJURP antibody (Abcam, ab100800; dilution, 1:500), anti-Mis18 $\alpha$ antibody (Thermo Fisher Scientific, PA5-53771; dilution, 1:500), antiSNAP-tag antibody (NEB, P9310; dilution, 1:1,000), anti- $\alpha$-tubulin antibody (Sigma, T9026; dilution, 1:8,000), anti-vinculin antibody (Sigma, V9131; dilution, 1:10,000), anti-mouse HRP-conjugated antibody (GE, NXA931-1ML; dilution, 1:10,000), antirabbit HRP-conjugated antibody (GE, NA934-1ML; dilution, 1:10,000).

CENP-A deposition experiment. HeLa cells were treated with $10 \mathrm{nM}$ HJURP Stealth RNAi siRNA targeting the $3^{\prime}$-untranslated region of HJURP gene (Thermo Fisher Scientific) or $10 \mathrm{nM}$ Mis18a siRNA ${ }^{12}$ using Lipofectamine RNAiMAX according to the manufacture's protocol of reverse transfection and were incubated in DMEM supplemented with 10\% tetracycline-free FBS, 2 mM l-glutamine, $100 \mathrm{U} \mathrm{mL}^{-1}$ Penicillin and $0.1 \mathrm{mg} \mathrm{mL}^{-1}$ Streptomycin (PAN-Biotech) at $37^{\circ} \mathrm{C}$ in the presence of $5 \% \mathrm{CO}_{2}$ for $48 \mathrm{~h}$. Doxycycline (Sigma) was added to the culture at a concentration of $50 \mathrm{ng} \mathrm{mL}^{-1}$ to induce protein expression and was kept in the media until the fixation of cells. Thymidine ( $1 \mathrm{mM}$ final concentration) was used to arrest cells at S/G1 transition phase. When cells were released from thymidine, existing SNAP-CENP-A proteins were blocked using SNAP-Cell Block or SNAPCell TMR-star (NEB) according to the manufacture's protocol. STLC ( $5 \mathrm{mM}$ final concentration) was used to arrest cells in prometaphase. The cells arrested in prometaphase were separated from other cells by mitotic-shake-off, released from STLC by extensive wash with the media and placed in wells of 24-well plates containing poly-lysine coated coverslips. Three hours later, the cells in early G1 phase attached on the coverslips and were treated with SNAP-Cell 647-SiR (NEB) to label newly synthesized SNAP-CENP-A according to the manufacture's protocol. Then the cells were incubated with pre-extraction buffer $(100 \mathrm{mM}$ sodium chloride, $300 \mathrm{mM}$ sucrose, $3 \mathrm{mM} \mathrm{MgCl}_{2}, 10 \mathrm{mM}$ PIPES pH 6.8, $0.1 \%$ Triton X100 ) on ice for 2 min and fixed with PBS containing $4 \%$ paraformaldehyde at room temperature for $20 \mathrm{~min}$.

The fixed cells were permeabilized with PBS-T (PBS buffer containing 0.1\% Triton X-100) for $10 \mathrm{~min}$ and incubated with PBS-T containing $4 \%$ BSA for $40 \mathrm{~min}$. CREST/anti-centromere antibody (Antibodies, Inc.; dilution, 1:200) and anti-human DyLight 405-conjugated secondary antibody (Jackson ImmunoResearch; dilution, 1:200) were used for immunostaining of the centromeres. After washing and drying, the coverslips were mounted with Mowiol mounting media (EMD Millipore) on glass slides and imaged using a $\times 60$ oil immersion objective lens on a DeltaVision deconvolution microscope. Quantification of centromere signals was performed using the software Fiji ${ }^{84}$ with a script for semiautomated processing. Briefly, average projections were made from $\mathrm{z}$-stacks of recorded images. Centromere spots were chosen based on the 
parameters of shape, size, and intensity using the images of the reference channel obtained with CREST-staining, and their positions were recorded. In the images of the data channels, the mean intensity value of adjacent pixels of a centromere spot was subtracted as background intensity from the mean intensity value of the centromere spot. Statistical analysis of the quantified intensity was performed using Microsoft Excel and the plots were generated using Matplotlib libraries.

Structure modeling of the Mis18 C-terminal helix-bundle. The structure model of the trimeric C-terminal helix-bundle of Mis $18 \alpha$ and Mis $18 \beta$ was made using CCBuilder 2.067. Amino-acid sequences of Mis18a Arg198-Phe227 and Mis18 $\beta$ Leu192-Val220 were used to generate a trimeric coiled-coil bundle. Chain 1 and chain 2 were assigned to Mis18a 198-227, and chain 3 to Mis18 $\beta$ 193-220. Radius was set to $6 \AA$, pitch to $200 \AA$, interface angle to $24^{\circ}$. The register of Mis 18 a Arg198 was set to "a", and the register of Mis18ß Leu192 to " $\mathrm{d}$ ".

Reporting summary. Further information on research design is available in the Nature Research Reporting Summary linked to this article.

\section{Data availability}

The mass spectrometry data have been deposited to the ProteomeXchange Consortium via the PRIDE partner repository with the dataset identifier PXD013339. All other relevant data supporting the key findings of this study are available within the article and its Supplementary Information files or from the corresponding authors upon reasonable request. The source data underlying Figs. 2, 3, 8 and Supplementary Figs. 3, 5, 6 are provided in a Source Data file. A reporting summary for this Article is available as a Supplementary Information file.

Received: 23 April 2019 Accepted: 16 August 2019

Published online: 06 September 2019

\section{References}

1. Musacchio, A., Desai, A. A Molecular View of Kinetochore Assembly and Function. Biology (Basel) 6 E5 (2017)

2. McKinley, K. L. \& Cheeseman, I. M. The molecular basis for centromere identity and function. Nat. Rev. Mol. Cell Biol. 17, 16-29 (2016).

3. Zasadzinska, E. \& Foltz, D. R. Orchestrating the specific assembly of centromeric nucleosomes. Prog. Mol. Subcell. Biol. 56, 165-192 (2017).

4. Fukagawa, T. \& Earnshaw, W. C. The centromere: chromatin foundation for the kinetochore machinery. Dev. Cell. 30, 496-508 (2014).

5. Ohzeki, J., Larionov, V., Earnshaw, W. C. \& Masumoto, H. De novo formation and epigenetic maintenance of centromere chromatin. Curr. Opin. Cell Biol. 58, 15-25 (2019).

6. Bodor, D. L. et al. The quantitative architecture of centromeric chromatin. elife 3, e02137 (2014).

7. Black, B. E. \& Cleveland, D. W. Epigenetic centromere propagation and the nature of CENP-a nucleosomes. Cell 144, 471-479 (2011).

8. Nardi, I. K., Zasadzinska, E., Stellfox, M. E., Knippler, C. M. \& Foltz, D. R. Licensing of centromeric chromatin assembly through the Mis18alphaMis18beta heterotetramer. Mol. Cell 61, 774-787 (2016).

9. Raychaudhuri, N. et al. Transgenerational propagation and quantitative maintenance of paternal centromeres depends on Cid/Cenp-A presence in Drosophila sperm. PLoS Biol. 10, e1001434 (2012).

10. Ross, J. E., Woodlief, K. S. \& Sullivan, B. A. Inheritance of the CENP-A chromatin domain is spatially and temporally constrained at human centromeres. Epigenetics Chromatin 9, 20 (2016).

11. Hayashi, T. et al. Mis16 and Mis18 are required for CENP-A loading and histone deacetylation at centromeres. Cell 118, 715-729 (2004).

12. Fujita, Y. et al. Priming of centromere for CENP-A recruitment by human hMis18alpha, hMis18beta, and M18BP1. Dev. Cell. 12, 17-30 (2007).

13. Foltz, D. R. et al. Centromere-specific assembly of CENP-a nucleosomes is mediated by HJURP. Cell 137, 472-484 (2009).

14. Dunleavy, E. M. et al. HJURP is a cell-cycle-dependent maintenance and deposition factor of CENP-A at centromeres. Cell 137, 485-497 (2009).

15. Dunleavy, E. M., Almouzni, G. \& Karpen, G. H. H3.3 is deposited at centromeres in S phase as a placeholder for newly assembled CENP-A in G(1) phase. Nucleus 2, 146-157 (2011).

16. Jansen, L. E., Black, B. E., Foltz, D. R. \& Cleveland, D. W. Propagation of centromeric chromatin requires exit from mitosis. J. Cell. Biol. 176, 795-805 (2007).

17. Schuh, M., Lehner, C. F. \& Heidmann, S. Incorporation of Drosophila CID/ CENP-A and CENP-C into centromeres during early embryonic anaphase. Curr. Biol. 17, 237-243 (2007).
18. Bodor, D. L., Valente, L. P., Mata, J. F., Black, B. E. \& Jansen, L. E. Assembly in G1 phase and long-term stability are unique intrinsic features of CENP-A nucleosomes. Mol. Biol. Cell 24, 923-932 (2013).

19. Smoak, E. M., Stein, P., Schultz, R. M., Lampson, M. A. \& Black, B. E. Longterm retention of CENP-A nucleosomes in mammalian oocytes underpins transgenerational inheritance of centromere identity. Curr. Biol. 26, 1110-1116 (2016)

20. Falk, S. J. et al. Chromosomes. CENP-C reshapes and stabilizes CENP-A nucleosomes at the centromere. Science 348, 699-703 (2015).

21. Maddox, P. S., Hyndman, F., Monen, J., Oegema, K. \& Desai, A. Functional genomics identifies a Myb domain-containing protein family required for assembly of CENP-A chromatin. J. Cell. Biol. 176, 757-763 (2007).

22. Ohzeki, J. et al. KAT7/HBO1/MYST2 regulates CENP-A chromatin assembly by antagonizing Suv39h1-mediated centromere inactivation. Dev. Cell. 37, 413-427 (2016)

23. Perpelescu, M., Nozaki, N., Obuse, C., Yang, H. \& Yoda, K. Active establishment of centromeric CENP-A chromatin by RSF complex. J. Cell. Biol. 185, 397-407 (2009).

24. Lagana, A. et al. A small GTPase molecular switch regulates epigenetic centromere maintenance by stabilizing newly incorporated CENP-A. Nat. Cell Biol. 12, 1186-1193 (2010).

25. Bernad, R. et al. Xenopus HJURP and condensin II are required for CENP-A assembly. J. Cell. Biol. 192, 569-582 (2011).

26. Barnhart-Dailey, M. C., Trivedi, P., Stukenberg, P. T. \& Foltz, D. R. HJURP interaction with the condensin II complex during G1 promotes CENP-A deposition. Mol. Biol. Cell 28, 54-64 (2017).

27. Shuaib, M., Ouararhni, K., Dimitrov, S. \& Hamiche, A. HJURP binds CENP-A via a highly conserved $\mathrm{N}$-terminal domain and mediates its deposition at centromeres. Proc. Natl Acad. Sci. USA 107, 1349-1354 (2010).

28. Sanchez-Pulido, L., Pidoux, A. L., Ponting, C. P. \& Allshire, R. C. Common ancestry of the CENP-A chaperones Scm3 and HJURP. Cell 137, 1173-1174 (2009).

29. Stoler, S. et al. Scm3, an essential Saccharomyces cerevisiae centromere protein required for G2/M progression and Cse4 localization. Proc. Natl Acad. Sci. USA 104, 10571-10576 (2007).

30. Camahort, R. et al. $\mathrm{Scm} 3$ is essential to recruit the histone h3 variant cse 4 to centromeres and to maintain a functional kinetochore. Mol. Cell 26, 853-865 (2007).

31. Mizuguchi, G., Xiao, H., Wisniewski, J., Smith, M. M. \& Wu, C. Nonhistone $\mathrm{Scm} 3$ and histones CenH3-H4 assemble the core of centromere-specific nucleosomes. Cell 129, 1153-1164 (2007)

32. Muller, S. et al. Phosphorylation and DNA binding of HJURP determine its centromeric recruitment and function in CenH3(CENP-A) loading. Cell Rep. 8, 190-203 (2014)

33. Zasadzinska, E., Barnhart-Dailey, M. C., Kuich, P. H. \& Foltz, D. R. Dimerization of the CENP-A assembly factor HJURP is required for centromeric nucleosome deposition. EMBO J. 32, 2113-2124 (2013).

34. Barnhart, M. C. et al. HJURP is a CENP-A chromatin assembly factor sufficient to form a functional de novo kinetochore. J. Cell. Biol. 194, 229-243 (2011).

35. French, B. T., Westhorpe, F. G., Limouse, C. \& Straight, A. F. Xenopus laevis M18BP1 directly binds existing CENP-A nucleosomes to promote centromeric chromatin assembly. Dev. Cell. 42, 190-199 e110 (2017).

36. Shono, N. et al. CENP-C and CENP-I are key connecting factors for kinetochore and CENP-A assembly. J. Cell. Sci. 128, 4572-4587 (2015).

37. Dambacher, S. et al. CENP-C facilitates the recruitment of M18BP1 to centromeric chromatin. Nucleus 3, 101-110 (2012).

38. Moree, B., Meyer, C. B., Fuller, C. J. \& Straight, A. F. CENP-C recruits M18BP1 to centromeres to promote CENP-A chromatin assembly. J. Cell. Biol. 194, 855-871 (2011)

39. Stellfox, M. E., Nardi, I. K., Knippler, C. M. \& Foltz, D. R. Differential binding partners of the Mis18alpha/beta YIPPEE domains regulate Mis18 complex recruitment to centromeres. Cell Rep. 15, 2127-2135 (2016).

40. Tachiwana, H. et al. HJURP involvement in de novo CenH3(CENP-A) and CENP-C recruitment. Cell Rep. 11, 22-32 (2015).

41. Perpelescu, M. et al. HJURP is involved in the expansion of centromeric chromatin. Mol. Biol. Cell 26, 2742-2754 (2015)

42. Logsdon, G. A. et al. Both tails and the centromere targeting domain of CENP-A are required for centromere establishment. J. Cell. Biol. 208, 521-531 (2015).

43. Sandmann, M. et al. Targeting of Arabidopsis KNL2 to centromeres depends on the conserved CENPC-k motif in its C terminus. Plant Cell 29, 144-155 (2017).

44. Hori, T. et al. Association of M18BP1/KNL2 with CENP-A nucleosome is essential for centromere formation in non-mammalian vertebrates. Dev. Cell. 42, 181-189 e183 (2017).

45. Kral, L. Possible identification of CENP-C in fish and the presence of the CENP-C motif in M18BP1 of vertebrates. F1000Res. 4, 474 (2015). 
46. French, B. T. \& Straight, A. F. CDK phosphorylation of Xenopus laevis M18BP1 promotes its metaphase centromere localization. EMBO J. 38 e100093 (2019)

47. Westhorpe, F. G., Fuller, C. J. \& Straight, A. F. A cell-free CENP-A assembly system defines the chromatin requirements for centromere maintenance. $J$. Cell. Biol. 209, 789-801 (2015).

48. Ding, M. et al. HJURP interacts with and specifies the centromeric assembly of CENP-T. J. Biol. Chem. 294 968-980 (2018).

49. McKinley, K. L. \& Cheeseman, I. M. Polo-like kinase 1 licenses CENP-A deposition at centromeres. Cell 158, 397-411 (2014).

50. Stankovic, A. et al. A dual inhibitory mechanism sufficient to maintain cell cycle-restricted CENP-A assembly. Mol. Cell 65, 231-246 (2017).

51. Wang, J. et al. Mitotic regulator Mis18beta interacts with and specifies the centromeric assembly of molecular chaperone holliday junction recognition protein (HJURP). J. Biol. Chem. 289, 8326-8336 (2014).

52. Pan, D. et al. CDK-regulated dimerization of M18BP1 on a Mis18 hexamer is necessary for CENP-A loading. Elife 6 e23352 (2017).

53. Silva, M. C. et al. Cdk activity couples epigenetic centromere inheritance to cell cycle progression. Dev. Cell. 22, 52-63 (2012).

54. Spiller, F. et al. Molecular basis for Cdk1-regulated timing of Mis18 complex assembly and CENP-A deposition. EMBO Rep. 18, 894-905 (2017).

55. Kato, H. et al. A conserved mechanism for centromeric nucleosome recognition by centromere protein CENP-C. Science 340, 1110-1113 (2013).

56. Klare, K. et al. CENP-C is a blueprint for constitutive centromere-associated network assembly within human kinetochores. J. Cell. Biol. 210, 11-22 (2015).

57. Weir, J. R. et al. Insights from biochemical reconstitution into the architecture of human kinetochores. Nature 537, 249-253 (2016).

58. Thakur, J. \& Henikoff, S. CENPT bridges adjacent CENPA nucleosomes on young human alpha-satellite dimers. Genome Res. 26, 1178-1187 (2016).

59. Ai, H. W., Shen, W., Sagi, A., Chen, P. R. \& Schultz, P. G. Probing proteinprotein interactions with a genetically encoded photo-crosslinking amino acid. Chembiochem 12, 1854-1857 (2011).

60. Chin, J. W., Martin, A. B., King, D. S., Wang, L. \& Schultz, P. G. Addition of a photocrosslinking amino acid to the genetic code of Escherichiacoli. Proc. Natl Acad. Sci. USA 99, 11020-11024 (2002).

61. Tighe, A., Johnson, V. L. \& Taylor, S. S. Truncating APC mutations have dominant effects on proliferation, spindle checkpoint control, survival and chromosome stability. J. Cell. Sci. 117, 6339-6353 (2004).

62. Subramanian, L. et al. Centromere localization and function of Mis18 requires Yippee-like domain-mediated oligomerization. EMBO Rep. 17, 496-507 (2016).

63. Shilton, B. H., Shuman, H. A. \& Mowbray, S. L. Crystal structures and solution conformations of a dominant-negative mutant of Escherichia coli maltose-binding protein. J. Mol. Biol. 264, 364-376 (1996).

64. Davis, L. \& Chin, J. W. Designer proteins: applications of genetic code expansion in cell biology. Nat. Rev. Mol. Cell Biol. 13, 168-182 (2012).

65. Lim, K. et al. Three-dimensional structure of Schistosoma japonicum glutathione S-transferase fused with a six-amino acid conserved neutralizing epitope of gp41 from HIV. Protein Sci. 3, 2233-2244 (1994).

66. Kaplan, W. et al. Conformational stability of pGEX-expressed Schistosoma japonicum glutathione S-transferase: a detoxification enzyme and fusionprotein affinity tag. Protein Sci. 6, 399-406 (1997).

67. Wood, C. W. \& Woolfson, D. N. CCBuilder 2.0: Powerful and accessible coiled-coil modeling. Protein Sci. 27, 103-111 (2018)

68. Zasadzinska, E. et al. Inheritance of CENP-A nucleosomes during DNA replication requires HJURP. Dev. Cell. 47, 348-362 e347 (2018).

69. Cho, U. S. \& Harrison, S. C. Recognition of the centromere-specific histone Cse4 by the chaperone Scm3. Proc. Natl Acad. Sci. USA 108, 9367-9371 (2011).

70. Dechassa, M. L. et al. Structure and Scm3-mediated assembly of budding yeast centromeric nucleosomes. Nat. Commun. 2, 313 (2011).

71. $\mathrm{Hu}, \mathrm{H}$. et al. Structure of a CENP-A-histone $\mathrm{H} 4$ heterodimer in complex with chaperone HJURP. Genes Dev. 25, 901-906 (2011).

72. Arias, E. E. \& Walter, J. C. Strength in numbers: preventing rereplication via multiple mechanisms in eukaryotic cells. Genes Dev. 21, 497-518 (2007).

73. Gibson, D. G. et al. Enzymatic assembly of DNA molecules up to several hundred kilobases. Nat. Methods 6, 343-345 (2009).

74. Petrovic, A. et al. The MIS12 complex is a protein interaction hub for outer kinetochore assembly. J. Cell. Biol. 190, 835-852 (2010).

75. Koh, E. Y. et al. An internal ribosome entry site (IRES) mutant library for tuning expression level of multiple genes in mammalian cells. PLoS One. 8 , e82100 (2013).

76. Young, T. S., Ahmad, I., Yin, J. A. \& Schultz, P. G. An enhanced system for unnatural amino acid mutagenesis in E. coli. J. Mol. Biol. 395, 361-374 (2010).

77. Chatterjee, A., Sun, S. B., Furman, J. L., Xiao, H. \& Schultz, P. G. A versatile platform for single- and multiple-unnatural amino acid mutagenesis in Escherichia coli. Biochemistry 52, 1828-1837 (2013).
78. Chou, C., Uprety, R., Davis, L., Chin, J. W. \& Deiters, A. Genetically encoding an aliphatic diazirine for protein photocrosslinking. Chem. Sci. 2, 480-483 (2011).

79. Shi, J. et al. Engineered red blood cells as carriers for systemic delivery of a wide array of functional probes. Proc. Natl Acad. Sci. USA 111, 10131-10136 (2014).

80. Schuck, P. Size-distribution analysis of macromolecules by sedimentation velocity ultracentrifugation and lamm equation modeling. Biophys. J. 78, 1606-1619 (2000)

81. Pan, D., Brockmeyer, A., Mueller, F., Musacchio, A. \& Bange, T. Simplified protocol for cross-linking mass spectrometry using the MS-cleavable crosslinker DSBU with efficient cross-link identification. Anal. Chem. 90, 10990-10999 (2018)

82. Chambers, M. C. et al. A cross-platform toolkit for mass spectrometry and proteomics. Nat. Biotechnol. 30, 918-920 (2012).

83. Gotze, M. et al. StavroX-a software for analyzing crosslinked products in protein interaction studies. J. Am. Soc. Mass. Spectrom. 23, 76-87 (2012).

84. Schindelin, J. et al. Fiji: an open-source platform for biological-image analysis. Nat. Methods 9, 676-682 (2012).

85. Larkin, M. A. et al. Clustal W and Clustal X version 2.0. Bioinformatics 23, 2947-2948 (2007).

86. Buchan, D. W., Minneci, F., Nugent, T. C., Bryson, K. \& Jones, D. T. Scalable web services for the PSIPRED Protein Analysis Workbench. Nucleic Acids Res. 41, W349-W357 (2013).

\section{Acknowledgements}

D.P. gratefully acknowledges support from the Alexander von Humboldt Foundation through Humboldt Research Fellowships. A.M. gratefully acknowledges funding by the Max Planck Society, the European Research Council (ERC) Advanced Investigator Grant RECEPIANCE (proposal number $n^{\circ}$ 669686), and the DFG's Collaborative Research Centre (CRC) 1093. We thank Heinz Neumann for sharing reagents and for help with the setup of the amber-codon suppression experiments. We thank all members of the Musacchio laboratory for helpful discussions and comments, and Franziska Müller and Andreas Brockmeyer for support of MS analysis.

\section{Author contributions}

D.P. generated plasmids. D.P., A.T., and D.B. purified proteins and performed biochemical assays. D.P., K.W., and A.T. created HeLa cell lines and performed CENP-A deposition assays and data analysis. D.P. performed AUC experiments and UV-crosslinking experiments. N.K. synthesized AbK. A.M. supervised and administered the research team. D.P. and A.M. wrote the manuscript with contributions from all authors

\section{Additional information}

Supplementary Information accompanies this paper at https://doi.org/10.1038/s41467 019-12019-6.

Competing interests: The authors declare no competing interests.

Reprints and permission information is available online at http://npg.nature.com/ reprintsandpermissions/

Peer review information: Nature Communications thanks Alexander Leitner and other anonymous reviewer(s) for their contribution to the peer review of this work. Peer reviewer reports are available.

Publisher's note: Springer Nature remains neutral with regard to jurisdictional claims in published maps and institutional affiliations.

Open Access This article is licensed under a Creative Common Attribution 4.0 International License, which permits use, sharing, adaptation, distribution and reproduction in any medium or format, as long as you give appropriate credit to the original author(s) and the source, provide a link to the Creative Commons license, and indicate if changes were made. The images or other third party material in this article are included in the article's Creative Commons license, unless indicated otherwise in a credit line to the material. If material is not included in the article's Creative Commons license and your intended use is not permitted by statutory regulation or exceeds the permitted use, you will need to obtain permission directly from the copyright holder. To view a copy of this license, visit http://creativecommons.org/ licenses/by/4.0/

(C) The Author(s) 2019 